\title{
Wave Run-Up on Offshore Wind Turbines
}





\section{Wave Run-Up on Offshore Wind Turbines}

Numerical and Experimental Results

PhD Thesis by

Jorge Ramirez

Department of Civil Engineering, The Faculty of Engineering and Science, Aalborg University, Aalborg, Denmark

River Publishers

Aalborg 
ISBN 978-87-92982-28-5 (e-book)

Published, sold and distributed by:

River Publishers

P.O. Box 1657

Algade 42

9000 Aalborg

Denmark

Tel.: +45369953197

www.riverpublishers.com

Copyright for this work belongs to the author, River Publishers have the sole right to distribute this work commercially.

All rights reserved (c) 2012 Jorge Ramirez.

No part of this work may be reproduced, stored in a retrieval system, or transmitted in any form or by any means, electronic, mechanical, photocopying, microfilming, recording or otherwise, without prior written permission from the Publisher. 


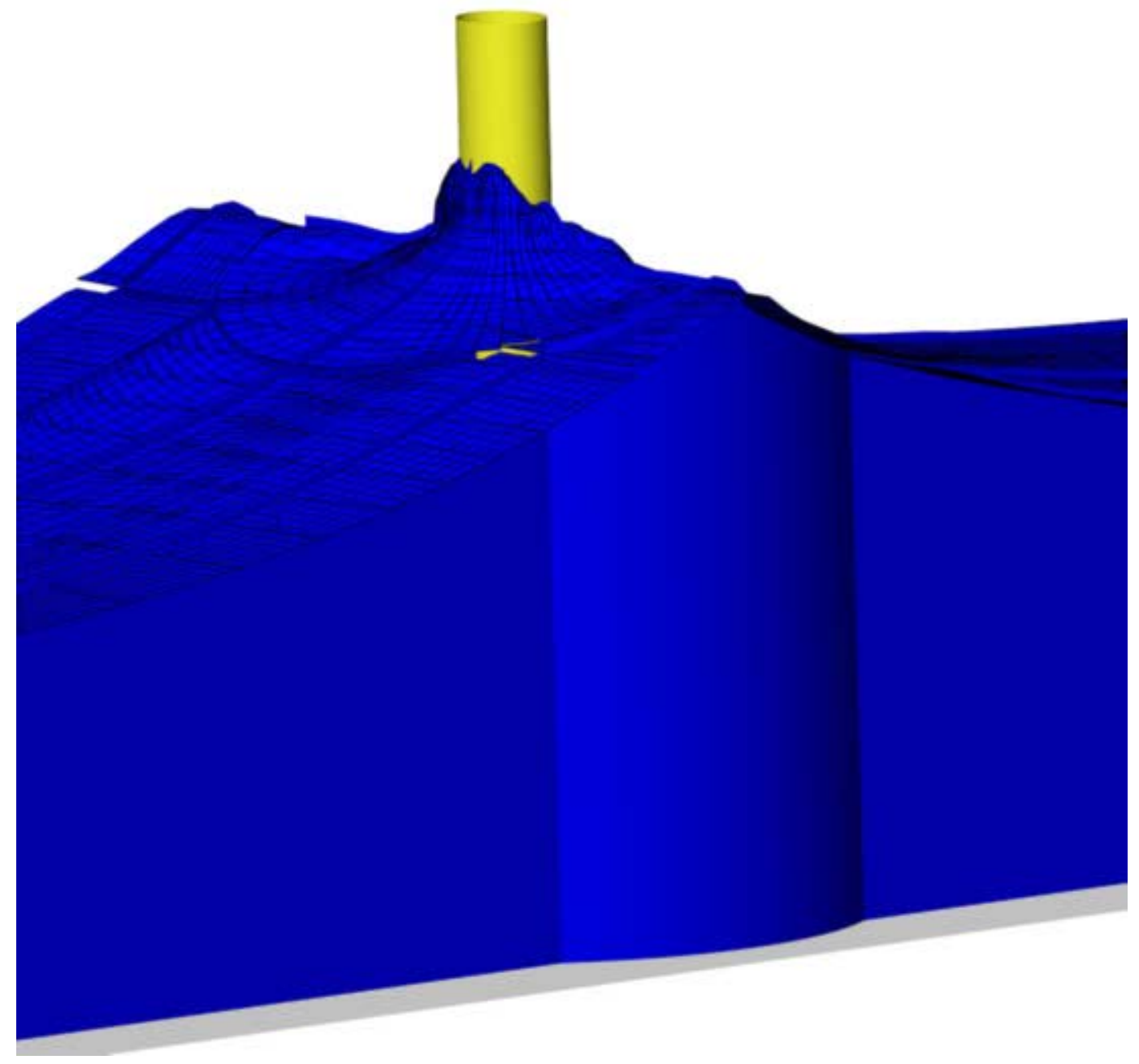



The present thesis is submitted as one of the requirements for the Danish Ministry of Education for the Danish Ph.D degree. The study was carried out at the Civil Engineering Department at Aalborg University, under the supervision of associate professor PhD. Peter Frigaard and associate professor Ph.D Thomas Lykke Andersen.

From September 2009 to May 2010, the study was conducted at the Danish Hydraulic Institute (DHI), where the numerical work was carried out, during this stay, currently associate professor at Technical University of Denmark (DTU), Ph.D Erik Damgaard Christensen, acted as a local supervisor, I sincerely thank him for his greatly support. The whole staff of DHI are thanked for their endless support and helpfulness during my stay, and special thanks are directed to Iris Pernille Logmann for her patience and invaluable help even when I was running simulations in Aalborg.

I am very grateful for the unceasing support and guidance from my supervisors Peter Frigaard and Thomas Lykke Andersen. Especially Peter, for the stimulus he gave me when I began this journey towards the Ph.D degree.

During this three years, I have met many persons, some of them are gone already, some of them were close friends than I keep in touch for instance Peres Akravi my officemate, Luiz Carlos former assistant professor at this department. I am thankful my closest friends Arthur Pecher, Anastasia Nezhentseva, John Lavelle, Andrew Zurkinden, Julia Chozas, Stefano Parmegiani, Parth, Prasad Chougule, Ivan Oropeza, Jose Ramirez, Nicolas Ratkovich, Femi Adisa, Manuel, Ines Olmedo, who have given me not just merely support and nice conversations at the corridors of the department even at my loudly office, but by listening and advising me during this time in Aalborg and Copenhagen.

Above all, I am grateful to Mamá and my siblings in Trujillo-Perú, since I began this challenge I found vastly support and strength in their voices through the telephone. One special mention to my little niece Gema Isabel Flores Rodriguez, I hope one day she can achieve the same goals than her uncle Cocó.

The thesis is presented as a collection of peer-reviewed articles published within this period in a journal and conferences. 


\section{Summary in English}

This study has investigated the interaction of water waves with a circular structure known as wave run-up phenomenon. This run-up phenomenon has been simulated by the use of computational fluid dynamic models.

The numerical model (NS3) used in this study has been verified rigorously against a number of cases. Regular and freak waves have been generated in a numerical wave tank with a gentle slope in order to address the study of the wave run-up on a circular cylinder. From the computational side it can be said that it is inexpensive. Furthermore, the comparison of the current numerical model presented in this thesis with the measured results from the experiments has shown a good agreement.

Besides this numerical study, model scale experiments have been conducted where the wave run-up on a slender circular cylinder in irregular sea state was measured with surface gauges located close to the cylinder. Based on appropriate analysis the collected data has been analysed with the stream function theory to obtain the relevant parameters for the use of the predicted wave run-up formula. An analytical approach has been pursued and solved for individual waves. Maximum run-up and 2\% run-up were studied to get a better understanding of the phenomenon. According to the results from this analysis it has been established that the run-up heights are largely influenced by the deep water wave steepness. Overall, the outcome of this research is that the simplified model presented in this thesis of the wave run-up on a slender circular cylinder is the most useful tool for platform designers.

\section{Summary in Danish}

Interaktionen mellem af vandbølger og en cirkulær konstruktion, det såkaldte "wave run-up" fænomen er undersøgt. Dette run-up fænomen er blevet simuleret ved brug af CFD modeller.

Den numeriske model (NS3) anvendt i dette studie er blevet verificeret på flere måder. Regelmæssige og såkaldte "monsterbølger" (freak- eller rogue waves) er blevet genereret i en numerisk bølgetank med en let hældning for at undersøge "wave run-up" på en cirkulær cylinder. Fra et beregningsmæssigt synspunkt er denne form for undersøgelse "billig". I øvrigt er den numeriske model præsenteret $i$ denne afhandling sammenlignet med de målte resultater fra forsøget og en god sammenhæng er observeret.

Udover denne numeriske undersøgelse, er et omfattende skalafors $\emptyset$ g udført. I fors $\emptyset$ get er "wave run-up" på en tynd cirkulær cylinder i en uregelmæssig søtilstand blevet målt med bølgemålere placeret tæt på cylinderen. Baseret på passende analysemetoder er de indsamlede data blevet analyseret med strømfunktionsteorien for at opnå de relevante parametre til brug i den af den forudsagte "wave run-up" formel. En analytisk tilgang er blevet fulgt og løst for individuelle bølger. Maksimal "run-up" og 2\% "run-up" er blev undersøgt for at opnå en bedre forståelse af fænomenet. Ifølge resultaterne fra denne analyse er det blevet fastslået, at "run-up" højder i høj grad er påvirket af bølgestejlheden på dybt vand. Samlet set er resultatet af dette studie, at den forenklede model af "wave run-up" på en slank cirkulær cylinder præsenteret i denne afhandling er det mest nyttigt redskab til platformsdesignere. 


\section{Contents}

1 Introduction 1

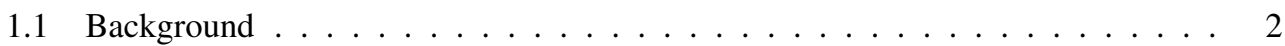

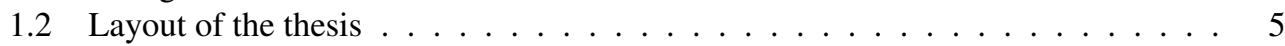

2 Theoretical Formulation $\quad 7$

2.1 Governing field equation $\ldots \ldots \ldots \ldots \ldots \ldots$

2.1.1 Boundary Conditions . . . . . . . . . . . . . . . . . . . 8

2.2 Spatial Discretisation of the Navier-Stokes Equations _ . . . . . . . . . . . 8

2.2.1 Discretisation of Boundary Conditions . . . . . . . . . . . . . . . 11

2.3 Free Surface Conditions . . . . . . . . . . . . . . . . . . . . 12

2.3.1 Discretised Free Surface Boundary Conditions . . . . . . . . . . . . . 13

2.4 Time Discretisation . . . . . . . . . . . . . . . . . . . . . . . . . . . . . . 14

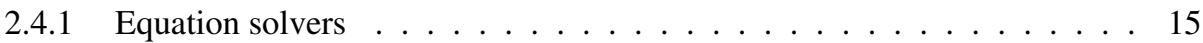

3 Free Surface Modelling 17

3.1 The Volume of Fluid Method . . . . . . . . . . . . . . . . . . . . . 17

3.1 .1 Discretised Equations . . . . . . . . . . . . . . . . . . . . . . . . . . . 19

3.2 Volume Fraction Differencing Schemes . . . . . . . . . . . . . . . 20

3.3 VOF Cleaning Routine . . . . . . . . . . . . . . . . . 23

4 Summary of the Results

4.1 Experimental Model . . . . . . . . . . . . . . . . . . . . 25

4.1.1 Wave conditions . . . . . . . . . . . . . . . . 25

$4.2 \quad \mathrm{NS3}$ model $\ldots \ldots \ldots \ldots \ldots$. . . . . . . . . . . . . . . . . . 30

$4.2 .1 \quad$ NS3 set-up . . . . . . . . . . . . . . . . . . . . . . . 30

4.2.2 Generation of waves: Numerical procedure . . . . . . . . . . . . 31

4.3 NS3 configuration . . . . . . . . . . . . . . . . . . . 32

4.4 CFD Outcomes . . . . . . . . . . . . . . . . . . . . . 32

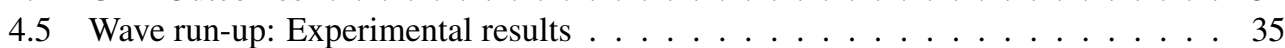

$5 \quad$ Future work and open questions 39

5.1 Concluding Remarks . . . . . . . . . . . . . . . . . . . . . . . 39

$\begin{array}{lr}\text { References } & 41\end{array}$ 
A Fourier Transform $\quad \mathbf{4 5}$

A.1 Note for using $\mathrm{fft}$ and ifft in MATLAB . . . . . . . . . . . . . . 45

B Stream Function Theory $\quad 47$

C Snapshots of the experimental campaign $\quad 51$ 


\section{List of Figures}

1.1 Wind energy . . . . . . . . . . . . . . . . . 2

1.2 Wave run-up on one of the towers of the Horns Reef, Danish wind farm . . . . . 3

1.3 Wave impacting on the cylinder ................. 4

2.1 Cell layout for $2 \mathrm{D}$ grid, $\Omega_{c}$ is shown in bold . . . . . . . . . . . . . 9

2.2 Discretisation of the free surface . . . . . . . . . . . . . 15

3.1 Cell arrangement . . . . . . . . . . . . . . . . . . 20

3.2 Normalised variable diagram with $\mathrm{CBC} \ldots \ldots \ldots \ldots$

4.1 Sketch of the wave tank . . . . . . . . . . . . . . . . . 26

4.2 Time series of the wave elevation of freak wave . . . . . . . . . . . . 26

4.3 Laboratory measured wave $T=6.0 \mathrm{~s} H=1.0 \mathrm{~m} \ldots \ldots$. . . . . . . . . . . 28

4.4 Laboratory wave elevation and Fourier coefficients obtained using FFT for focused waves. . . . . . . . . . . . . . . . . . . . . . . . . . . . . . 29

$4.5 \mathrm{NS3}$ grid built $\ldots \ldots \ldots \ldots \ldots \ldots \ldots \ldots \ldots$

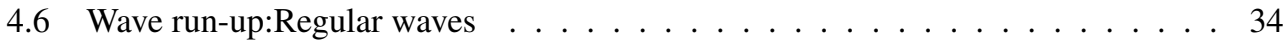

4.7 Wave run-up:Focused waves . . . . . . . . . . . . . . . . . . 34

4.8 Proposed adjustment $m$ factor plotted against deep water wave steepness. Wave kinematics are computed by stream function theory using $H_{\max }$ for $R_{u, \max }$, $H_{2 \%}$ for $R_{u, 2 \%}$ and $T_{p}$ in both cases. . . . . . . . . . . . . . . 36

4.9 Comparison of the wave run-up predicted versus estimated, using Eqs. (4.2)(4.4) for $2 \%$ and maximum run-up levels. . . . . . . . . . . . . . . . . . 37

C.1 Overview of the flume . . . . . . . . . . . . . . . . 52

C.2 Snapshot of the breaking waves impacting on the cylinder. Wave conditions

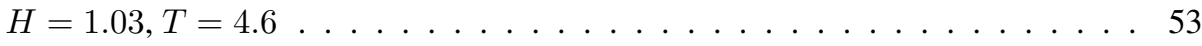

C.3 Snapshot of the breaking waves impacting on the cylinder. Wave conditions $H=1.03, T=4.6 \ldots \ldots \ldots \ldots$. . . . . . . . . . . . . . . . .

C.4 Snapshot of the breaking waves impacting on the cylinder. Wave conditions $H=1.03, T=4.6 \ldots \ldots \ldots \ldots$ 


\section{List of Tables}

2.1 General boundary conditions for pressure and velocity. . . . . . . . . . . 8

3.1 Volume fraction schemes $0 \leq \widetilde{\alpha}_{D} \leq 1 \ldots \ldots \ldots \ldots \ldots$

4.1 Distances from wave generator to the instruments. . . . . . . . . . . . . . 27

4.2 Experimental conditions for validation with NS3 model(model scale). . . . . . . 27

4.3 Experimental conditions for irregular sea state (model scale). . . . . . . . . . . 27 


\section{ChAPTER 1 Introduction}

In this chapter the statement of the problem is described and a historical review of the problem address in this thesis is shown. It is pointed out the use of different techniques to address the wave run-up, showing the pro and cons of the methods applied to tackle the problem. At the end it is outlined in brief the contents of each of the chapters

Wind power is widely seen as the source of renewable energy with the best chance of competing with fossil-fuel power stations in the near term see Fig. 1.1. The European Union has a target to turn at least $20 \%$ of its electricity supply from renewable energy sources, mainly wind power, by 2020. In the recent decades the wind energy sector have developed faster, It seems as a very promising source to generate electricity. However, problems as the pollution of the landscape, noise have arisen. Several wind energy companies have started installing offshore wind turbine mainly because the wind blows stronger than in land, but cost of energy is much higher offshore due to higher installation and maintenance costs cover the turbine itself but also damages due to extreme wave run-up have been seen. Nowadays many offshore wind farms can be seen in european coastlines. The wave run-up, splash, green water (the term "green water" is used to distinguish between the spray flying around and the real solid seawater on the structure), etc are of very complicated nature and analytical solutions are not available, except in simple cases. In has been reported that offshore wind turbines exposed to storm condition, where severe wave run-up can occur causing significant damage on the entrance platforms see Fig. 1.2.

The wave run-up is when an incident wave impinges on a body penetrating the free surface, the wave undergoes a violent transformation where some portion of the incident wave's momentum is directed vertically upward see Fig.1.3. To conserve energy, this momentum flux results in a rapid amplification of the wave form at the free surface body interface. This is highly non-linear phenomena and is particularly important for air gap design. Numerical simulations with Computational Fluid Dynamic (CFD) models and physical experiments have largely carried out, concentrated in wave run-up investigations on piles, lighthouses, breakwaters, sloped beaches and columns of offshore structures. Therefore a better understanding of the wave run-up is necessary to be able to make a reliable and cost-effective design of the platforms and ladders around the offshore wind turbine. 


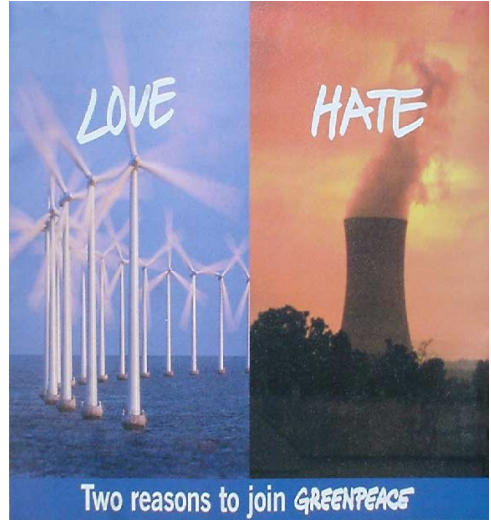

(a) Greenpeace leaflet

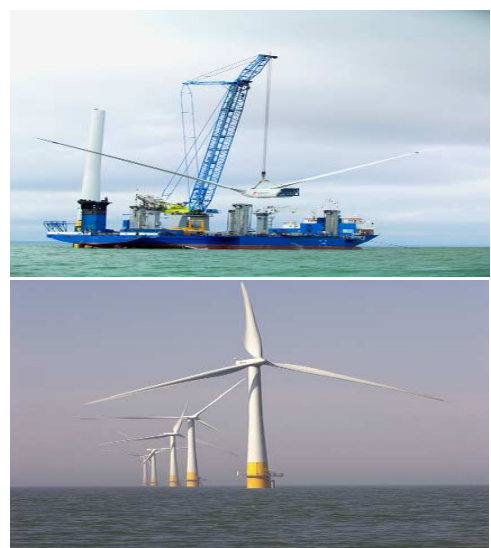

(b) A shallow offshore wind farm. Photo (c)Elsam, used with permission.

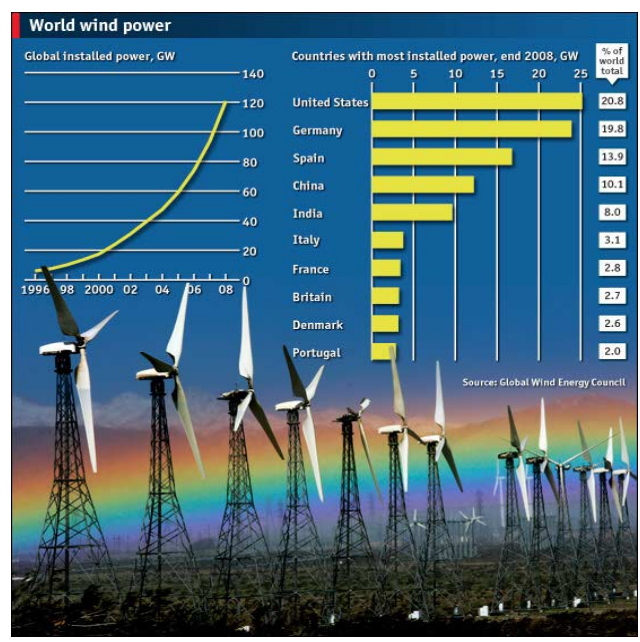

(c) World wind power. Graphic (c)The Economist, used with permission

Figure 1.1: Wind energy

\subsection{Background}

The cause of wave run-up have long been investigated and many hypothetical mechanisms have been proposed from different point of view. Over the last decades great progress has been made in the understanding of the physical mechanisms of wave run-up phenomenon. Experimental studies and numerical simulations were performed to obtain enough information to predict with high accuracy this phenomena. In the wind energy sector the knowledge of the wave run-up is fundamental for deciding the distance from the still water level to the platform deck.

As the computational power has grown during the last decades, a new tool to tackle this problem appeared for performing new studies, however the computational cost is very high and 

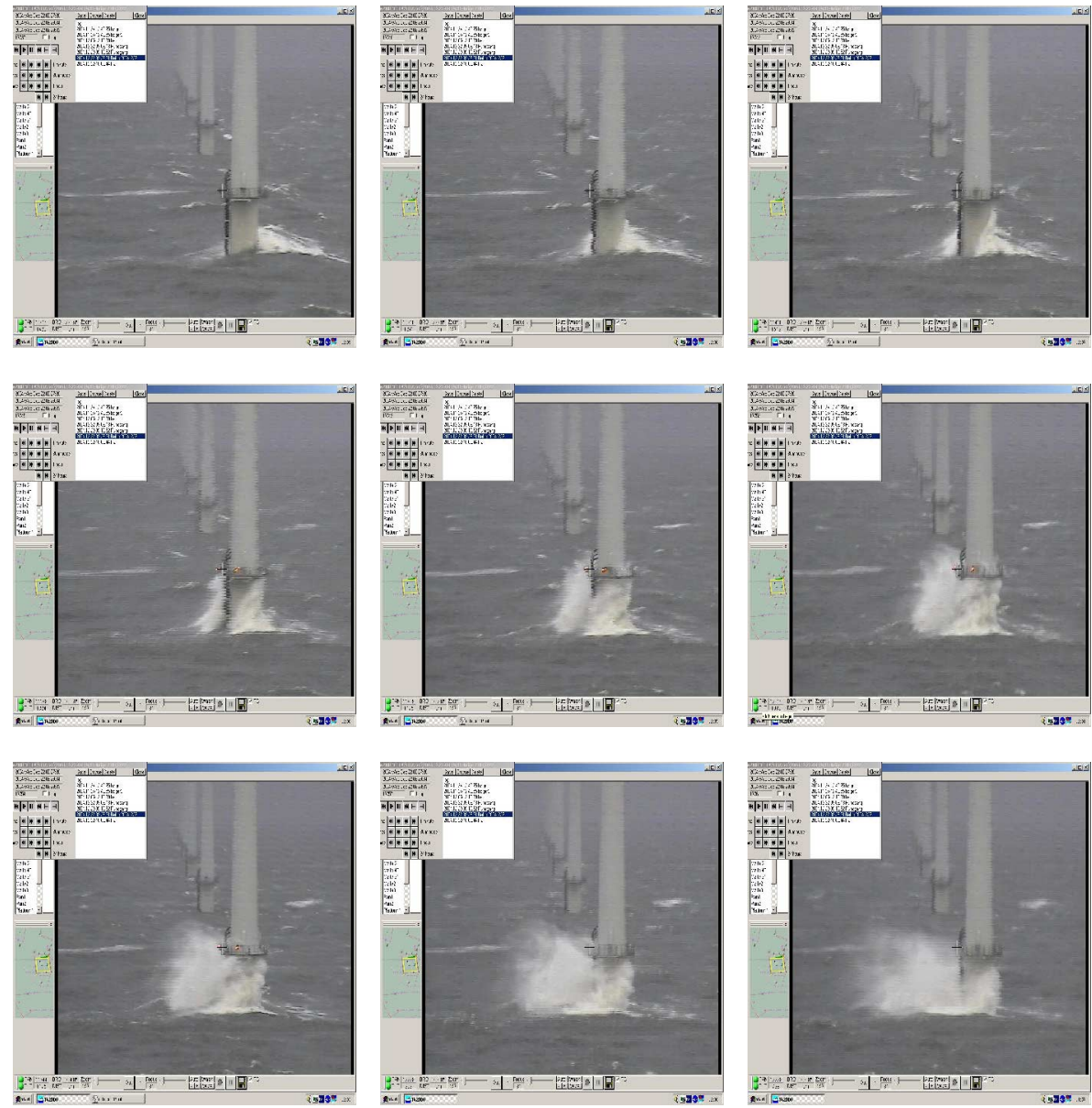

Figure 1.2: Wave run-up on one of the towers of the Horns Reef, Danish wind farm

still the numerical models are limited by lack of accuracy. Based on numerical models, a simplified analytical procedure has been presented by (Kriebel 1992). Based on the boundary integral equation method BEM (Isaacson and Cheung 1993) have studied the wave run-up on a cylinder with the interaction of current. Corresponding (Buchmann and Cheung 1997), (Buchmann and Skourup 1998), (Buchmann 1999) have used the frequency domain to perform calculations and analyze the run-up height.

3D models, performed by CFD codes have given a powerful contribution to improve the understanding of the wave run-up, as this phenomenon is a highly non-linear process and perhaps a more efficacious approach is to solve the exact free surface boundary condition directly in the time domain. The set of Navier-Stokes equations are suitable to described this phenomenon because are highly versatile, allowing simulate complex problems as breaking waves, air entrainment, fluid-structure interaction just to mention few. (Sterndorff 2002), (Nielsen 2003), (Nielsen and Mayer 2004), (Christensen 2005), (Christensen 2008), (Ramirez and Christensen 2011). They have performed studies using the CFD model, NS3 developed by DHI, which is based on 

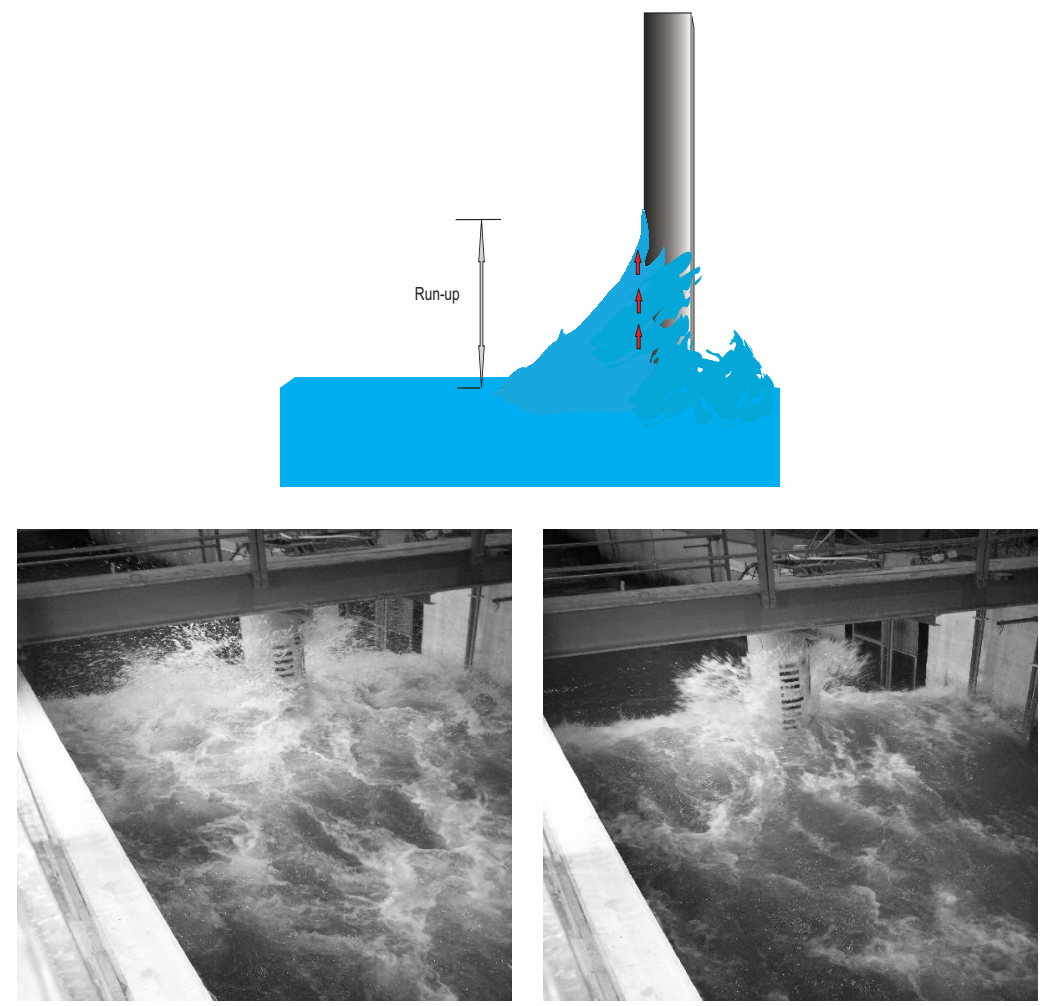

Figure 1.3: Wave impacting on the cylinder

the solution of Navier-Stokes equations and use the VOF method for the treatment of the free surface.

There are several codes available that can be used to solve this kind of problem, some of them are commercial and in-house software, for instance (Buchner and Veldman 2001), (Kleefsman 2005b), (Kleefsman 2005a), The have used the CFD software COWFLOW, which is a solver of 3D Navier-Stokes with an improved Volume of Fluid (iVOF) method. (Morris-Thomas and Thiagarajan 2004), (Morris-Thomas and Thiagarajan 2007), have performed calculations with a commercial software FLUENT. The main setback with those CFD models is at the present they are extremely more computationally expensive than other numerical method mentioned earlier.

Many were carried out different kind of experiments have been carried out, and a few of them will be mentioned in the following. The first notable contribution in the experimental work into wave run-up was performed by (Hallermeier and Galvin 1972). (Chakrabarty and Tam 1975) have studied the wave run-up on a vertical circular cylinder in regular waves. (Kriebel 1990) have used the second order diffraction theory to study the wave run-up with monochromatic waves. A circular cylinder was exposed to regular and random waves in the work by (Niedzwecki and Duggal 1992). Most recent experimental investigations have carried out by (Martin 2001), .(De Vos 2007), They have been used the second order Stoke's theory to predict the run up using stagnation head theory. (Lykke Andersen T. 2010) have used the stream function theory to reanalyzed De Vos's data and performed new tests, They concluded the wave steepness plays 
an important role in the run-up heights for breaking and nearly breaking waves. (Myrhaug and Holmedal 2010), (Myrhaug 2011), have used the data from (De Vos 2007) and analyzed, based on the velocity stagnation head theory and second order irregular wave theory.

\subsection{Layout of the thesis}

In the following, the outline of the thesis will be given. Basically, the thesis can be divided into three main parts. Chapter 2 is describing the numerical model that have been used to solve the problem. It includes detailed description of the governing equations. The general solution procedure is presented, along with a description of the applied spatial and time discretisation. In chapter 3 the treatment of the free surface is described by the use of the Volume of Fluid method (VOF). Chapter 4 resumes the main results from the the numerical model and the experimental large scale tests. To complete the thesis the concluding remarks are presented, along with further suggestions for future research. As appendix three papers are presented. The firsts two papers are comparing experimental results against numerical results obtained from the computational software in order to validate the NS3 model, which should help to address the feasibility of numerical models with this sort of phenomena. The last paper is analyzing the collected data obtained from the model experiments with the prediction method for three different levels of run-up heights for individual incident waves. In addition the study for the $R_{u, \max }$ and $R_{u, 2 \%}$ are also included. It is given a better understanding of the formula to calculate the wave run-up in large scale models. 


\section{CHAPTER 2 Theoretical Formulation}

The fluid flow is a continuum phenomenon where a set of Navier-Stokes equations represents its behavior with good approximation. This set of equations has been applied in the study of hydrodynamics with big success. Different methods have been used to solve these equations numerically. With the current rate of evolution of computational power is common find many commercial programmes as CFX, Fluent and STAR-CCM+ available for solving the NavierStokes equations with the approach of wave-structure interaction.

In the present thesis it has been chosen an in-house programme named NS3, this code was originally developed at the International Research Center for Computational Hydrodynamics (ICCH Høsholm, Denmark), and different versions of it have previously been presented by (Kawamura and Sørensen 1997) (Mayer and Sørensen 1998), and (Kawamura and Sørensen 2002). During recent years this code has been modified and applied to fluid flow modelling see (Christensen 2005), (Christensen 2008). Although NS3 is not a commercial programm, the close contact with the main developers gave very efficiency support and cooperation with the user. In this and the next chapter, the description of the numerical model is highly inspired by the documents provided by DHI, which are not published, it shows the governing equations and the solution procedure.

\subsection{Governing field equation}

The mathematical equations that describe the motion of the fluid flow can be written in different forms, in the present section it has been chosen the integral form. The advantage of this approach is more physical and also the discretisation of the equations has nice numerical properties. Thereby the continuity equation, demanding conservation of mass, then becomes

$$
\oint_{\Gamma} \mathbf{u} \cdot \mathbf{n} d \Gamma=0
$$

Conservation of momentum can be written in its incompressible form, also know as the incompressible Navier-Stokes equations

$$
\frac{\partial}{\partial t} \int_{\Omega} \mathbf{u} d \Omega=-\oint_{\Gamma}(u \otimes u) \cdot \mathbf{n} d \Gamma-\oint_{\Gamma} p \mathbf{n} d \Gamma+\frac{1}{R e} \oint_{\Gamma} \nabla \mathbf{u} . \mathbf{n} d \Gamma
$$

where $\mathbf{n}$ is the outward pointing normal vector at the boundary $\Gamma$ of a volume element $\Omega, t$ is time, $R e$ is the Reynolds number, $\mathbf{u}$ is the cartesian velocity vector, and $\otimes$ is the outer vector product operator. The Reynolds number $R e$ is defined as

$$
R e=\frac{U L}{\nu}
$$


with $U$ and $L$ as characteristic velocity and length parameters, and $\nu$ is the kinematic viscosity. The pressure variable $p$ is defined as the derivation from hydrostatic pressure given by

$p=\tilde{p}+g x_{3}$

where $\tilde{p}$ is static pressure, $g$ is gravitational acceleration and $x_{3}$ is the cartesian coordinate in the direction of gravitation. Eqs. (2.1)-(2.2) are given for an Eulerian grid (e.g. fixed in time) but can be extended to arbitrary Eulerian-Lagragian by including grid velocity in the convective term, which is the first on the right side of Eq. (2.2). Various turbulence models have also been implemented in the code, but since turbulent effects are considered negligible for the applications regarded in this thesis, turbulence modelling is omitted.

\subsubsection{Boundary Conditions}

To solve the governing equations boundary conditions are needed at the walls of the numerical domain and the free surface. In this section the boundary conditions of the free surface are excepted. Overall two types of boundary conditions are applied: Dirichlet and Neumann type condition. The Dirichlet condition states that

$\varphi_{b}=r$

and the Neumann condition that

$\frac{\partial \varphi_{b}}{\partial \mathbf{n}}=r$

where $\varphi_{b}$ is the value at the boundary for the variable $\varphi$ and $r$ is a constant. In general a Neumann condition is used for the pressure except when periodic boundary conditions are applied, this is done by setting the pressure gradient equal to zero at the boundaries. For pressure and velocity, the boundary conditions for the different types of outer boundary are given in Table 2.1.

Table 2.1: General boundary conditions for pressure and velocity.

\begin{tabular}{lrl}
\hline & $p_{b}$ & \multicolumn{1}{c}{$\mathbf{u}_{b}$} \\
\hline inflow $\left(x_{1}=\right.$ inflow $)$ & $\frac{\partial p_{b}}{\partial n}=0$ & $\mathbf{u}_{i, b}=\left\{u_{\text {inflow }}, 0\right\}$ \\
outflow & $p_{b}=0$ & $\frac{\partial u_{i, b}}{\partial n}=0$ \\
body surface & $\frac{\partial p_{b}}{\partial n}=0$ & $u_{i, b}=0$ \\
symmetry plane $\left(x_{1}=\right.$ symm $)$ & $\frac{\partial p_{b}}{\partial n}=0$ & $\frac{\partial \partial_{i, 1}}{\partial n}=0, \quad u_{i, 2}=0$ \\
free surface & $\tilde{p_{b}}=0$ & $\frac{\partial \mathbf{u}}{\partial n_{f_{s}}}$ \\
\hline
\end{tabular}

\subsection{Spatial Discretisation of the Navier-Stokes Equations}

The numerical solution of the Navier-Stokes equations is done by discretisation of Eqs.(2.1-2.2).

The common way of solving these set of equations is to solve the momentum equations and the 
continuity equation separately. This section describes the finite difference scheme to calculate the velocity field.

The numerical domain can be divided into a number of blocks forming a multiblock domain but, for simplicity, the discretisation procedure will here be derived for a single block. The discretisation scheme and the solution routine follow (Zang and Koseff 1994). When the classic finite volume method is applied, the domain is discretised by subdivision into smaller non-overlapping control volumes $\Omega_{c}$, also denoted cells. The whole domain containing all cells is termed the grid or the computational grid. Cartesian based structured grids are used in the present method, containing quadrilateral and hexahedral cells for two and three dimensions respectively. A cell-centered variable arrangement is used for the discretisation scheme, and the governing equations are solved by use of the primitive variables of pressure and velocity. For a cell $\Omega_{c}$ with the cell boundary $\Gamma_{c}$ the surface integrals can be discretised as a sum over the cells faces $\Gamma_{f}$, and in discrete form the governing equations Eqs.(2.1)-(2.2) can be rewritten as

$\sum_{f} \oint_{\Gamma_{f}} \mathbf{u} \cdot \mathbf{n} d \Gamma$

and

$\frac{\partial}{\partial t} \int_{\Omega_{c}} \mathbf{u} d \Omega=-\sum_{f} \oint_{\Gamma_{f}}(\mathbf{u} \otimes \mathbf{u}) \cdot \mathbf{n} d \Gamma-\sum_{f} \oint_{\Gamma_{f}} p \mathbf{n} d \Gamma+\frac{1}{R e} \sum_{f} \oint_{\Gamma_{f}} \nabla \mathbf{u} \cdot \mathbf{n} d \Gamma$

where $\sum_{f} \Gamma_{f}=\Gamma_{c}$ and $\sum_{c} \Omega_{c}=\Omega_{c}$. A collocated arrangement is used where the dependent variables of velocity and pressure are located at cell centres. Fig. 2.1 illustrates the curvilinear discretised domain for a two-dimensional case. The cells faces east, west, south and north will in the following be denoted $e, w, s$ and $n$. The integral over control volumes and surfaces for the various terms in Eqs. (2.7)-(2.8) are evaluated in the following using single-point quadrature.

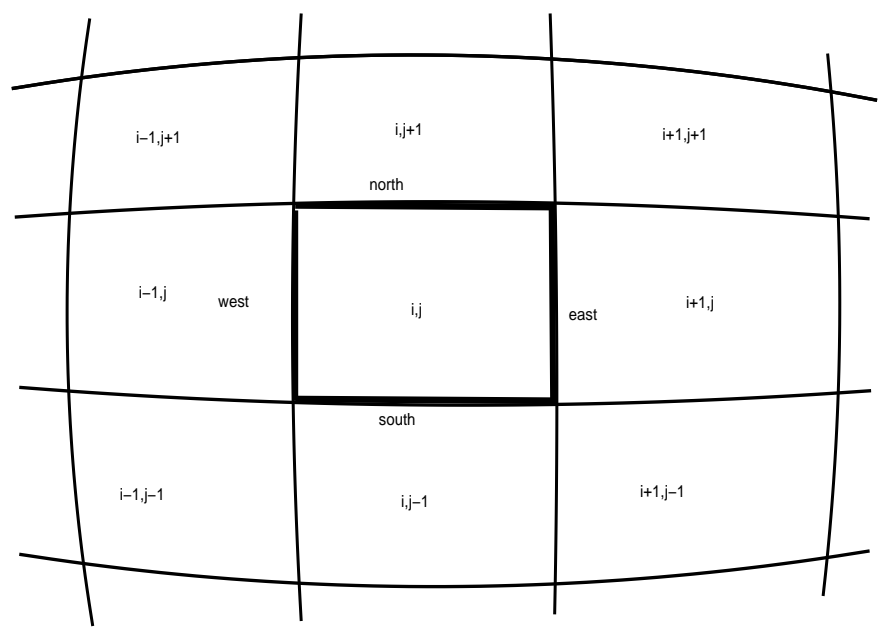

Figure 2.1: Cell layout for 2D grid, $\Omega_{c}$ is shown in bold 


\section{Divergence Term}

The mass equation Eq.(2.7) states that the velocity field must be divergence free, and the face integral can be reduced as

$\sum_{f} \oint_{\Gamma_{f}} \mathbf{u} . \mathbf{n} d \Gamma=\sum_{f} \mathbf{u}_{f} \cdot \mathbf{A}_{f}$

where $\mathbf{A}_{f}$ is the area weighted face normal vector and $\mathbf{u}_{f}$ is the velocity vector at the cell face $f$. The interpolation of velocity, from cell centre to cell face, for the mass equation is discussed in Section 2.4.

\section{Transient Term}

For the transient term, i.e. the time derivation term in Eq. (2.8), the cell integral can be reduced to

$\frac{\partial}{\partial t} \int_{\Omega_{c}} \mathbf{u} d \Omega=\frac{\partial}{\partial t} V_{c} \mathbf{u}_{c}$

in which $V_{c}$ is the cell volume and $\mathbf{u}_{c}$ is the velocity vector at the cell centre

\section{Convective Term}

The convective term represents the advection of momentum through the boundaries of volume $\Gamma_{f}$. The fluid transport (convection) term can be reduced to

$$
\left.\begin{array}{rl}
\sum_{f} \oint_{\Gamma_{f}}(\mathbf{u} \otimes \mathbf{u}) \cdot \mathbf{n} d \Gamma & =\sum_{f} \oint_{\Gamma_{f}} \mathbf{u}(\mathbf{u} . \mathbf{n}) d \Gamma \\
& =\sum_{f} Q_{f}\left(u_{c}\right) F_{i}
\end{array}\right\}
$$

Here $\mathbf{u}_{f}$ is the face of the velocity, $F_{i}$ is the face flux defined as

$F_{i}=\mathbf{u}_{i} \cdot \mathbf{A}_{i}$

and $Q_{f}$ represents an interpolation scheme for determining the velocity at the face from the cell centre values. The QUICK scheme (Leonard 1991) is applied in the present model, and for the east face $(e)$ of cell $i, j$ (see Fig. 2.1) it gives

$Q_{e}\left(\mathbf{u}_{i, j}\right)=\frac{1}{2}\left(\mathbf{u}_{i, j}+\mathbf{u}_{i+1, j}\right)-\frac{1}{8}\left(\mathbf{u}_{i-1, j}-2 \mathbf{u}_{i, j}+\mathbf{u}_{i+1, j}\right)$ 


\section{Pressure Term}

For the pressure, the face integral can be reduced to

$\sum_{f} \oint_{\Gamma_{f}} p \mathbf{n} d \Gamma=\sum_{f} I_{f}\left(p_{c}\right) \mathbf{A}_{f}$

where the linear interpolation operator $I_{f}$ is applied to the pressure to find the values at the cell faces. $I_{f}$ gives the value at the east face of the $i, j$ cell by

$I_{e}\left(p_{i, j}\right)=\frac{1}{2}\left(p_{i+1, j}+p_{i, j}\right)$

\section{Diffusion Term}

The final term in the momentum equation is the diffusion term, which is numerically integrated from

$\frac{1}{R e} \sum_{f} \oint_{\Gamma_{f}} \nabla \mathbf{u} . \mathbf{n} d \Gamma=\frac{1}{R e} \sum_{f} \mathbf{G}_{f}\left(\mathbf{u}_{c}\right) \mathbf{A}_{f}$

where $\mathbf{G}_{f}$ is an operator which evaluates the gradient of $\mathbf{u}_{c}$, including cross derivative terms, at the cell face $f$. In the 2-D case for the east face of cell $i, j$, the operator $\mathbf{G}_{f}$ gives

$$
\begin{aligned}
\mathbf{G}_{e}\left(\mathbf{u}_{i, j}\right)= & \frac{\mathbf{A}_{i, j, e}}{\frac{1}{2}\left(V_{i, j}+V_{i+1, j}\right)}\left(\mathbf{u}_{i+1, j}-\mathbf{u}_{i, j}\right) \\
& \frac{\frac{1}{4}\left(\mathbf{A}_{i, j, s}+\mathbf{A}_{i, j, n}+\mathbf{A}_{i+1, j, s}+\mathbf{A}_{i+1, j, n}\right)}{\frac{1}{2}\left(V_{i, j}+V_{i+1, j}\right)} \\
& \times \frac{1}{4}\left(\mathbf{u}_{i, j+1}-\mathbf{u}_{i, j-1}+\mathbf{u}_{i+1, j+1}-\mathbf{u}_{i+1, j-1}\right)
\end{aligned}
$$

\subsubsection{Discretisation of Boundary Conditions}

For the general variable $\varphi$ the linear interpolation scheme $I(\varphi)$ and the QUICK scheme $Q(\varphi)$ are , for a Dirichlet type boundary condition where the boundary condition $\varphi$ is implicitly known, given by

$I_{b}(\varphi)=Q_{b}(\varphi)=\varphi_{b}$

which means that the Dirichlet condition is given directly from Eq. (2.5) and Eq. (2.18). The gradient operator determines the boundary cell value based on second order one-sided differences, and is for the east face of cell $i, j$, for the same Dirichlet condition, given by

$$
\begin{aligned}
G_{b}(\varphi)_{i, j, e}= & \frac{\mathbf{A}_{i, j, e}}{\frac{3}{2} V_{i, j}-\frac{1}{2} V_{i-1, j}}\left(\frac{8}{3} \varphi_{b}-\frac{9}{3} \varphi_{i, j}+\frac{1}{3} \varphi_{i-1, j}\right) \\
& \frac{\frac{3}{4}\left(\mathbf{A}_{i, j, s}+\mathbf{A}_{i, j, n}\right)-\frac{1}{4}\left(\mathbf{A}_{i+1, j, s}+\mathbf{A}_{i+1, j, n}\right)}{\frac{3}{2} V_{i, j}-\frac{1}{2} V_{i-1, j}}\left(\frac{3}{4}\left(\varphi_{i, j+1}-\varphi_{i, j-1}\right)\right. \\
& \left.-\frac{1}{4}\left(\varphi_{i-1, j+1}-\varphi_{i-1, j-1}\right)\right)
\end{aligned}
$$


Moreover, the value at the boundary $\varphi_{b}$ for the Neumann condition can be found by solving

$\mathbf{G}_{b}(\varphi) \cdot \mathbf{A}_{b}=r$

\subsection{Free Surface Conditions}

In this section we addressed the most important property of the flow, which is the presence of a free surface. The proper discretisation is required to captured its dynamics.

\section{Kinematic condition}

The kinematic condition of the free surface requires the surface to move and deform as a material surface. If there is no overturning wave, the free surface is expressed in terms of a height function

$x_{3}=h\left(x_{1}, x_{2}, t\right)$

where $\left(x_{1}, x_{2}, x_{3}\right)$ are the cartesian coordinate. The kinematic free surface condition is written as

$\frac{\partial h}{\partial t}=-u_{1} \frac{\partial h}{\partial x_{1}}-u_{2} \frac{\partial h}{\partial x_{2}}+u_{3}$

The computational grid $\left(\xi_{1}, \xi_{2}, \xi_{3}\right)$ is fitted to the free surface, where $\xi_{3}=$ const plane corresponds to the free surface. Therefore, the grid is regenerated every time step according to the free surface movement.

two different schemes are used to discretise Eq. (2.22), and the appropriate one is chosen depending on the character of the problem and according to the integration scheme for the momentum equation. Eq.(2.22) is discretised as

$\frac{\partial h}{\partial t}=\frac{u_{i} n_{i}}{n_{i} e_{i}}$

where, $n_{i}$ is the normal area vector of the surface, and $e_{i}$ is a unit vector in the direction in which the surface point moves. The expression of Eq. (2.23) assures that the fluid volume flux through the cell face equals the volume swept by the grid movement. The third order explicit AdamthBashforth method is used for the time integration of Eq. (2.23). The other scheme is used for steady or slowly varying flows, in which an upwind differencing and implicit time integration are used for the sake of the numerical stability. Since the surface gradient terms, $\frac{\partial h}{\partial x_{1}}$ and $\frac{\partial h}{\partial x_{2}}$, are included in Eq. (2.23) as the normal area vector , it i difficult to integrate implicitly. Therefore, the following difference scheme is also used.

$\frac{\partial h}{\partial t}=-u_{1}\left(\frac{\partial h}{\partial \xi_{1}} \frac{\partial \xi_{1}}{\partial x_{1}}+\frac{\partial h}{\partial \xi_{2}} \frac{\partial \xi_{2}}{\partial x_{1}}\right)-u_{2}\left(\frac{\partial h}{\partial \xi_{1}} \frac{\partial \xi_{1}}{\partial x_{2}}+\frac{\partial h}{\partial \xi_{2}} \frac{\partial \xi_{2}}{\partial x_{2}}\right)+u_{3}$

The spatial derivative terms in Eq. (2.24) are evaluated by a third order upwind differencing scheme, and the time integration is carried out by a semi-implicit scheme using a similar procedure to the momentum equation. 


\section{Dynamic free surface condition}

The conservation of the momentum across the liquid gas interface gives rise to the dynamic condition for the stress field:

$\sigma_{i, j}^{l i q} n_{j}=\sigma_{i, j}^{g a s} n_{j}+\gamma \kappa_{i}$

where the superscripts ${ }^{l i q}$ and ${ }^{g a s}$ denote quantities in the liquid layer ad the gas layer, respectively, and $n_{j}, \gamma$ and $\kappa$ are the unit outward normal vector of the free surface, $\gamma$ is the surface tension and the mean curvature, respectively. $\sigma_{i, j}$ is the stress tensor, which is written as

$\sigma_{i, j}=\nu\left(\frac{\partial u_{i}}{\partial x_{j}}+\frac{\partial u_{j}}{\partial x_{i}}\right)-\tilde{p} \delta_{i, j}$

where $\delta_{i, j}$ is Kronecker delta. However, in the applications considered in the present work, the viscous boundary layer on the surface and the effect of the surface tension can be considered negligible, which gives the following condition for pressure

$\tilde{p}=0$

Since the pressure variable which is solved for includes gravitational acceleration, the following boundary condition is imposed:

$p_{f s}^{n+1}=-g\left(x_{f s}^{n+1}-x_{f s, 0}\right)$

where $p_{f s}^{n+1}$ is the pressure on the free surface at the new time step, $x_{f s}^{n+1}$ is the free surface location at the new time step $n+1$, and $x_{f s, 0}$ is the initial free surface location. For the velocity, the general kinematic boundary condition 2.24 imposes a Dirichlet type condition on the free surface. However, since near surface boundary layers are considered negligible, no boundary condition is present for velocity. In order to find values at the cell face for the velocity field near the free surface, an extrapolation scheme is applied which satisfies the homogeneous Neumann condition on the free surface, i.e. .

$\frac{\partial \mathbf{u}}{\partial n_{f s}}=0$

where $n_{f s}$ is the normal vector to the free surface.

\subsubsection{Discretised Free Surface Boundary Conditions}

The discretisation of the free surface is shown in Fig. 2.2 When the Laplace operator is constructed for solving the pressure Poisson equation or the Poisson equation for the velocity correction, the values of a variable $\varphi$ at the north cell face for cell $i, j$ are found by second order one sided extrapolation, i.e. by forcing a second order polynomial through the values at $i, j$ and $i, j-1$ along with the value $\mathrm{n}$ the free surface location. The operator which satisfies the inhomogeneous Dirichlet condition Eq.(2.5) gives the following value at the north cell face

$E_{V D, n}\left(\varphi_{c}\right)=\frac{1}{3+8 l+4 l^{2}}\left(\left(9 l+6 l^{2}\right) \varphi_{i, j} \mathbf{A}_{i, j, n}+\left(-1-2 l^{2}\right) \varphi_{i, j-1} \mathbf{A}_{i, j, s}+3 r\right)$ 
where $E_{V}$ is the operator for the value at the face nearest to the free surface, and $l$ is the distance from the face to the discretised free surface (see Fig. 2.2). the derivative operator, which satisfies the same inhomogeneous Dirichlet condition on the discretised free surface location, gives the following in the face normal direction:

$$
E_{D D, n}\left(\varphi_{c}\right)=\frac{1}{3+8 l+4 l^{2}}\left((-9+4 l) \varphi_{i, j} \mathbf{A}_{i, j, n}+\left(1-4 l^{2}\right) \varphi_{i, j-1} \mathbf{A}_{i, j, s}+8 r\right)
$$

Similarly, the operator, leading to the value at the face that satisfies the homogeneous Neumann condition Eq. (2.6) with $r=0$ on the free surface is given by

$$
E_{V N, n}\left(\varphi_{c}\right)=\frac{1}{8+8 l}\left((9+12 l) \varphi_{i, j} \mathbf{A}_{i, j, n}+(-1-4 l) \varphi_{i, j-1} \mathbf{A}_{i, j, s}\right)
$$

Finally, the operator leading to the derivative of the value in the face normal direction that satisfies the homogeneous Neumann condition at the free surface is given by

$$
E_{D N, n}\left(\varphi_{c}\right)=\frac{1}{8+8 l}\left((9+12 l) \varphi_{i, j} \mathbf{A}_{i, j, n}+(-1-4 l) \varphi_{i, j-1} \mathbf{A}_{i, j, s}\right)
$$

these operators $E_{V D}, E_{D D}, E_{V N}$ and $E_{D N}$ are all used implicitly in the solution of the Poisson equations. In cases where the cell opposite to the face (in this case $i, j-1$ ) is not a fluid cell, a first order extrapolation scheme is applied.

\subsection{Time Discretisation}

The time integration of the velocity field is carried out by a second order fractional step method, being close to that of (Zang and Koseff 1994). However, it is extended to moving grids by an approach similar to that of Rosenfeld et al. . Assume that solutions for velocity and pressure are known up to time step $t^{n}$, and grid and boundary conditions have been set for $t^{n+1}$. The velocity field at time $t^{n+1}$ is split into a predictor velocity field $u^{*}$. Using an explicit Adams-Bashforth type scheme for the convective term and the pressure forcing, the momentum equation Eq. (2.8) is discretised as:

$$
\begin{aligned}
\frac{V_{c}}{\triangle t}\left(\mathbf{u}_{c}^{*}-\mathbf{u}_{c}^{n}\right)= & \left(\frac{3}{2} Q_{f}\left(\mathbf{u}_{c}^{n}\right) I_{f}\left(u u_{c}^{n}\right)-\frac{1}{2} Q_{f}\left(\mathbf{u}_{c}^{n-1}\right) I_{f}\left(u u_{c}^{n-1}\right)\right) \mathbf{A}_{f} \\
& -\left(\frac{3}{2} I_{f}\left(p_{c}^{n}\right)-\frac{3}{2} I_{f}\left(p_{c}^{n-1}\right)\right) \mathbf{A}_{f}+\frac{1}{2 R e}\left(\mathbf{G}_{f}\left(\mathbf{u}_{c}^{*}\right)+\mathbf{G}_{f}\left(\mathbf{u}_{c}^{n}\right)\right) \mathbf{A}_{f}
\end{aligned}
$$

When Eq. (2.34) is solved intermediate values for velocities are obtained, which does not satisfy the mass conservation equation. Therefore the velocity field is corrected by the field $\phi$, which is found by solving the following Poisson equation:

$\sum_{f} \mathbf{G}_{f}\left(\mathbf{G}_{c}(\phi)\right) \cdot \mathbf{A}_{f}=-\sum_{f} I_{f}\left(\mathbf{u}_{c}^{*}\right) \cdot \mathbf{A}_{f}$

Where $\mathbf{G}_{c}$ is the gradient operator that determines the gradient of the field at the $(i, j)$ cell centre by

$$
\mathbf{G}_{c}=\frac{1}{2 V_{c}}\left[\left(\mathbf{u}_{i+1, j}+\mathbf{u}_{i, j}\right) \mathbf{A}_{i, j, w}-\left(\mathbf{u}_{i-1, j}+\mathbf{u}_{i, j}\right) \mathbf{A}_{i, j, e}+\left(\mathbf{u}_{i, j+1}+\mathbf{u}_{i, j}\right) \mathbf{A}_{i, j, n}-\left(\mathbf{u}_{i, j-1}+\mathbf{u}_{i, j}\right) \mathbf{A}_{i, j, s}\right]
$$


When $\phi$ has been found the velocity field can be corrected at the new time step by

$\mathbf{u}_{c}^{n+1}=\mathbf{u}_{c}^{*}-\mathbf{G}_{c}(\phi)$

Finally, the pressure flied must be computed at the new time level. This is done by taking the divergence of the momentum equation, which gives the following Poisson equation for pressure:

$$
\begin{aligned}
\sum_{f} \mathbf{G}_{f}\left(\mathbf{G}_{c}\left(p^{n+1}\right)\right) \cdot \mathbf{A}_{f}= & -\sum_{f} \mathbf{G}_{f}\left(\sum_{f}\left[Q_{f}\left(\mathbf{u}_{c}^{n+1}\right) I_{f}\left(\mathbf{u}_{c}^{n+1}\right) \cdot \mathbf{A}_{f}\right]\right) \cdot \mathbf{A}_{f} \\
& +\sum_{f} \mathbf{G}_{f}\left(\sum_{f}\left[Q_{f}\left(\mathbf{u}_{c}^{n+1}\right) I_{f}\left(\mathbf{u}_{c}^{n+1}\right) \cdot \mathbf{A}_{f}\right]\right) \cdot \mathbf{A}_{f}+
\end{aligned}
$$

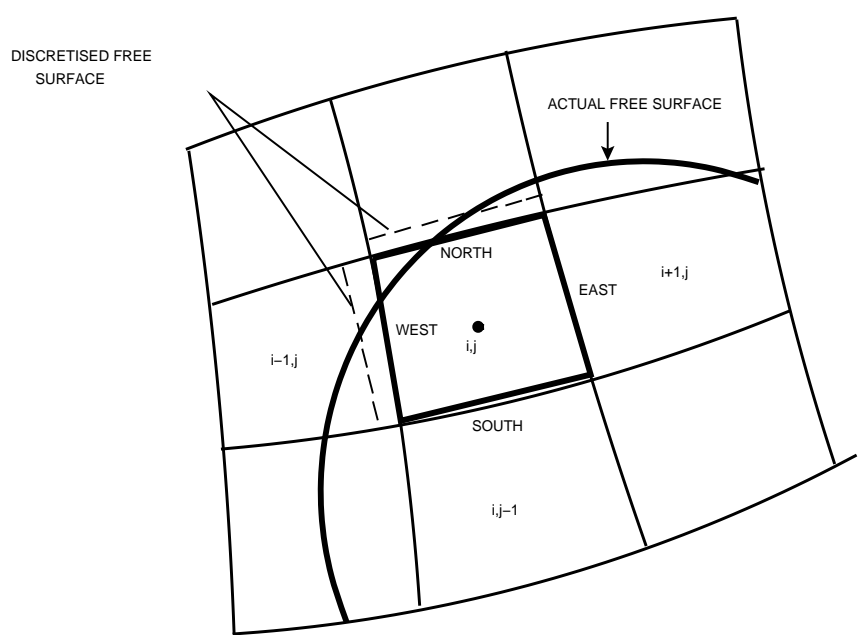

Figure 2.2: Discretisation of the free surface

\subsubsection{Equation solvers}

The first estimate velocities at the new time step (the predictor step ), found from Eq. (2.34), results in a linear equation system, which is solved by applying an iterative solver, using GaussSeidel line relaxation. The Poisson equations for the velocity corrector $\phi$ and for the pressure $p$ are solved by using the plane ILLU (Incomplete Line Lower Upper decomposition) solver applied on a V-cycle multigrid method.

\section{Overall Solution Procedure}

The overall solution procedure for the Navier-Stokes solver can be described by the following steps:

- Predictor step: Solve the discretised momentum equation Eq.(2.34) using the iterative Gauss-Seidel solver to obtain estimates of velocities $\mathbf{u}_{c}^{*}$ at the new time step. 
Corrector step 1 Solve the Poisson equation Eq. (2.35) for the velocity corrector $\phi$.

- Corrector step 2 Correct the intermediate velocity field $\mathbf{u}_{c}^{*}$ by $\phi$ using Eq. (2.37), so that $\mathbf{u}_{c}^{n+1}$ is divergence free.

- Compute pressure Solve the Poisson equation for pressure Eq. (2.38) at the new time step using the multigrid Poisson solver.

In the next section the free surface modelling scheme and the VOF method are addressed in detail. 


\section{CHAPTER 3 Free Surface Modelling}

The treatment of the free surface is of particular interest to engineers using CFD models to analyze hydrodynamics flows. In the following chapter we outlined and comment some methods but the aim of this chapter is described the method used by NS3 code.

One easy implementation to modelled the free surface can be the method of height functions, this method gives the position of the free surface in every vertical column of cells. The new height at a new time step is found by the velocity and slope at the surface or by a continuity equation for the vertical column of cells. The disadvantage of this method is when the surface is not located vertical, thereby it is impossible to used the method to simulate freak waves. A second way of tracking the surface on an unstructured grid is the use of the volume methods. The common basic idea is determining where the whole fluid is situated. The interface between the fluid and the non-fluid defines the position of the surface. The first of the volume of methods was the marker-cell method (MAC) developed by (Harlow and Welch 1965), one disadvantage of this method arises when the number of cell increases. (Hirt and Nichols 1981) developed a new method where they tracked the fluid by a continuity equation for a $F$ function. The main advantage of this method is the ability to capture complex surface geometries with overturning or breaking waves and splashing, but the drawback is the possibility of numerical instability, diffusivity (with blurred interface) or grid alignment. However, these issues have been dealt in many recent implementations using VOF schemes (Muzaferija and Schellin 1998); (Ubbink 1997), and in general the surface capturing methods show promising results. This method has gained attention in recent years and also been improved by many researchers. Another method is widely used in the hydrodynamic field and becoming popular in this area is the Smoothed Particle Hydrodynamic (SPH) (Monaghan 1992), initially invented to simulate phenomena in astrophysics, this is characterized because is a meshless method. Particles are put in the flow and every particle has a mass and velocity. The SPH method can handle large deformations of the fluid interface automatically, but seems very unstable. It should be mentioned that the main difficulty in dealing with free surfaces is that the position and shape of the free surface is not known, other than at the initial stage; its location at the later times has to be determined as part of the solution.

In the present study the surface tracking is made by the use of the VOF method. NS3 code also has a surface tracking scheme implemented, as reported in (Mayer and Sørensen 1998).

\subsection{The Volume of Fluid Method}

Since the first introduction of VOF methods in the seventies and eighties of the last century, they have become very popular. In this overview a selection of the literature gives a general idea of the VOF methods, which are often classed by two features: 
$\checkmark$ How to reconstruct the interface.

$\checkmark$ Method for advecting the interface.

For the interface reconstruction two main methods are in use. Firstly, the simple line interface calculation (SLIC) by (Kim 2008), where the interface is said to be parallel with one of the coordinate axes. (Hirt and Nichols 1981) also use a SLIC kind of reconstruction, which is not performed explicitly, but in this method within a cell a stair stepped interface form can be created.

The second method was first used (Young 1987), where a piecewise linear interface calculation (PLIC) is done. The piecewise linear reconstruction is much more accurate than a piecewise constant, which is why it is used in most of the recent VOF publications (Kleefsman 2005b). The disadvantage of the PLIC method is that it is more complicated than SLIC, specially in three dimensions. It is not easy to find a method for a piecewise planar reconstruction of the interface that is accurate and efficient.

After the interface has been reconstructed, it is advected. The advection can be done direction split or multidimensional. in the direction split approach the interface is reconstructed after which it is advected in the first coordinate direction. Then, a new reconstruction is made and the advection in the second coordinate direction is done based on the new reconstruction. For symmetry, the order of the directions should be alternated. In multidimensional methods, there is only one reconstruction after which the advection is done in all directions simultaneously. In three dimensional computations direction split is mostly used, because it is very difficult to construct a multidimensional method for a proper flux calculation in three dimensions.

For the calculation of fluxes, many different methods are in use. Some are Lagrangian methods in the sense that markers are placed on the reconstructed interface.

In the original VOF method introduced by (Hirt and Nichols 1981) no explicit reconstruction of the interface is performed. To compute the VOF function at the new time level, fluxes are calculated over every cell face using a donor acceptor method (Ubbink 1997).

Generally, the direction of the velocity defines whether a cell becomes a donor or acceptor cell. The basis of the volume of fluid method is that to each cell an additional scalar is assigned which is the VOF value giving the degree of filling for the cell. A cell with a volume fraction value of 0 is void, and a volume fraction value of 1 equals a full cell. If the value is between 0 and 1 the cell contains a free surface i.e.

$\alpha=\frac{\text { volume of fluid in cell }}{\text { total cell volume }}$

where $\alpha$ is the volume fraction and $1-\alpha$ is the volume fraction of the void or the air in the cell. Initially, all cell are given a volume fraction value, and at each time step a transport equation is solved to find the distribution of the fluid at the new time step:

$\frac{\partial \alpha}{\partial t}+\nabla \cdot \alpha \mathbf{u}=0$

where $t$ is time and $\mathbf{u}$ is the velocity vector.

Within the VOF methods two different approaches are possible: one is to neglect the effect of air in surface and void cells and only solve the equations on the cells with a volume fraction value different from 0 (one fluid approach), and the other is to solve the Navier-Stokes equations in all cells, treating the interface as a shift in fluid properties (two fluid approach). The present study is based on one fluid approach, but the equations and derivations can easily be extended to a two fluid approach see (Ubbink 1997). The boundary conditions are described in chapter 2. 


\subsubsection{Discretised Equations}

In integral form over the control volume and with time step $\delta t$, Eq. (3.2) is written as

$\int_{t}^{t+\delta t}\left(\int_{\Omega} \frac{\partial \alpha}{\partial t} d \Omega\right) d t+\int_{t}^{t+\delta t}\left(\int_{\Omega} \nabla \cdot \alpha \mathbf{u} d \Omega\right) d t=0$

In a constant volume cell (labelled c) where $\Omega_{c}$ is the volume, the first term of Eq. (3.3) can be reduced to

$$
\begin{aligned}
\int_{t}^{t+\delta t}\left(\int_{\Omega} \frac{\partial \alpha}{\partial t} d \Omega\right) d t & =\int_{t}^{t+\delta t}\left(\frac{\partial \alpha}{\partial t} \Omega_{c}\right) d t \\
& =\left(\alpha_{c}^{t+\delta t}-\alpha_{c}^{t}\right) \Omega_{c}
\end{aligned}
$$

Gauss'theorem can be applied to the volume integral in the second term (convection term) of Eq (3.3):

$$
\int_{\Omega} \nabla \cdot \alpha \mathbf{u} d \Omega=\oint_{\partial \Gamma} \alpha d \Gamma \cdot \mathbf{u} \approx \sum_{f=1}^{n} \alpha_{f} \mathbf{A}_{f} \cdot \mathbf{u}_{f}=\sum_{f=1}^{n} \alpha_{f} F_{f}
$$

where $d \Gamma$ is the surface area vector, $f$ indicates the face value, $\mathbf{A}_{f}$ is the discretised face area vector and $n$ is the number of faces. $F_{f}$ is the volumetric flux defined as:

$F_{f}=\mathbf{A}_{f} \cdot \mathbf{u}_{f}$

To calculate the time integral of Eq. (3.5) the formulation is introduced :

$\int_{t}^{t+\delta t}\left(\sum_{f=1}^{n} \alpha_{f} F_{f}\right) d t=\sum_{f=1}^{n}\left((1-\eta)\left[\alpha_{f} F_{f}\right]^{t}+\eta\left[\alpha_{f} F_{f}\right]^{t+\delta t}\right) \delta t$

where $\eta$ is a weighting factor for time integration. The following are most commonly used:

$\downarrow \eta=0$, for explicit calculations

$\downarrow \eta=1$, for implicit calculations

$\checkmark \eta=0.5$, for a Crank-Nicholson type scheme.

Here the Crank-Nicholson scheme is used. The second term on the right hand side of Eq. (3.7) shows that a velocity field at the newtime step is needed as part of the solution to the implicit VOF equation. in the present implementation, the new $\alpha$ filed is found before the normal solution algorithm is started, where the velocity and pressure are integrated to the new time step. This means that $F_{f}^{t+\delta t}$ is not available at the time when Eq. (3.7) is solved. Since the variation in $F$ can be considered negligible compared to the variation of $\alpha$, the volumetric flux of the previous time step can be used. An Adams-Bashforth scheme is applied, which is used to give an estimate of the flux field at $t+\delta t$ as

$F_{f, A B}^{t+\delta t}=\left(\frac{3}{2} \mathbf{u}^{t}-\frac{1}{2} \mathbf{u}^{t-\delta t}\right) \cdot \mathbf{A}_{f}$ 
where $F_{f, A B}^{t+\delta t}$ is the flux field at the new time step predicted by Adams-Bashforth scheme. in the following this flux field will just be denoted $F_{f}$. This gives the following formulation of Eq. (3.7):

$\left(\alpha_{c}^{t+\delta t}-\alpha_{c}^{t}\right)=\sum_{f=1}^{n} \frac{1}{2}\left(\alpha_{f}^{t}+\alpha_{f}^{t+\delta t}\right) F_{f} \delta t$

hence, the final formulation for the volume fraction at time step $t+\delta t$ becomes:

$\alpha_{c}^{t+\delta t}=\alpha_{c}^{t}-\frac{1}{\Omega_{c}} \sum_{f=1}^{n} \frac{1}{2}\left(\alpha_{f}^{t}+\alpha_{f}^{t+\delta t}\right) F_{f} \delta t$

In the following section, the different schemes for calculating the volume fraction at the cell faces $\left(\alpha_{f}\right)$ are described

\subsection{Volume Fraction Differencing Schemes}

To have a common reference throughout the computational domain, the definition of the cell arrangement is shown in Fig. 3.1. Here $\alpha_{D}$ is the volume fraction of the donor cell, $\alpha_{A}$ is the volume fraction of the acceptor cell and $\alpha_{U}$ is the volume fraction of the upwind cell. $\alpha_{f}$ is the volume fraction at the face between the donor and acceptor cells. The figure only shows the cell arrangement in one dimension, but can be extended to two and three dimensions.

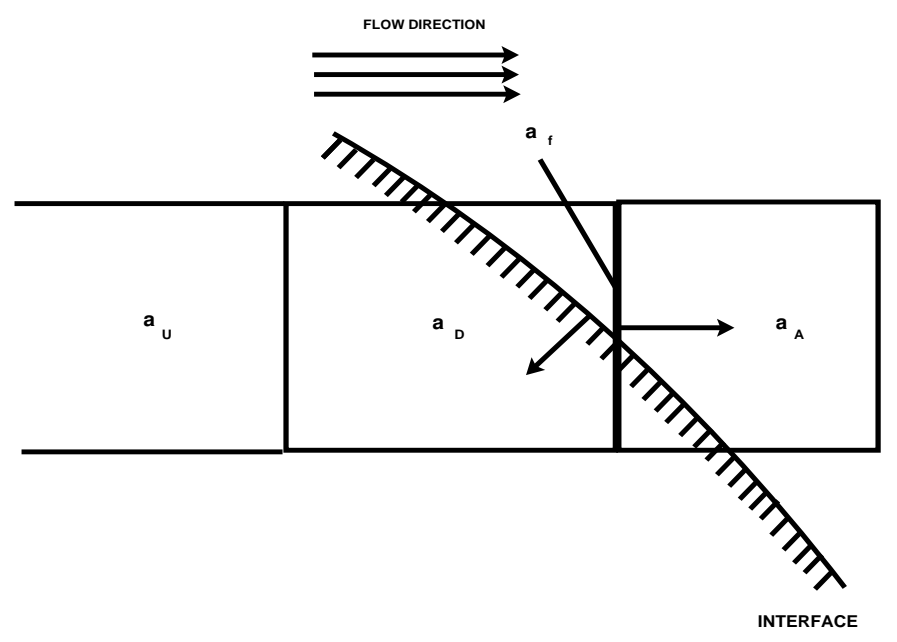

Figure 3.1: Cell arrangement

The schemes considered here are based on normalised variables. The definition of a normalised variable is:

$\widetilde{\alpha}=\frac{\alpha-\alpha_{U}}{\alpha_{A}-\alpha_{U}}$

The normalised donor cell centre value is given from Eq. 3.11 
$\widetilde{\alpha_{D}}=\frac{\alpha_{D}-\alpha_{U}}{\alpha_{A}-\alpha_{U}}$

where $\alpha_{D}$ is the donor cell volume fraction and $\widetilde{\alpha_{D}}$ is the normalised value of the donor cell volume fraction. A normalised variable diagram is a graphical way of showing how the normalised volume fraction at the cell face $\widetilde{\alpha_{f}}$ is calculated from the normalised donor cell centre value $\widetilde{\alpha_{D}}$. Fig. 3.2 presents a sketch of a normalised variable diagram with the boundaries for upwind and downwind differencing. These boundaries constitute the Convection Boundedness Criteria (CBC) for implicit calculations assuring local boundedness, and they are shown in the shaped region.

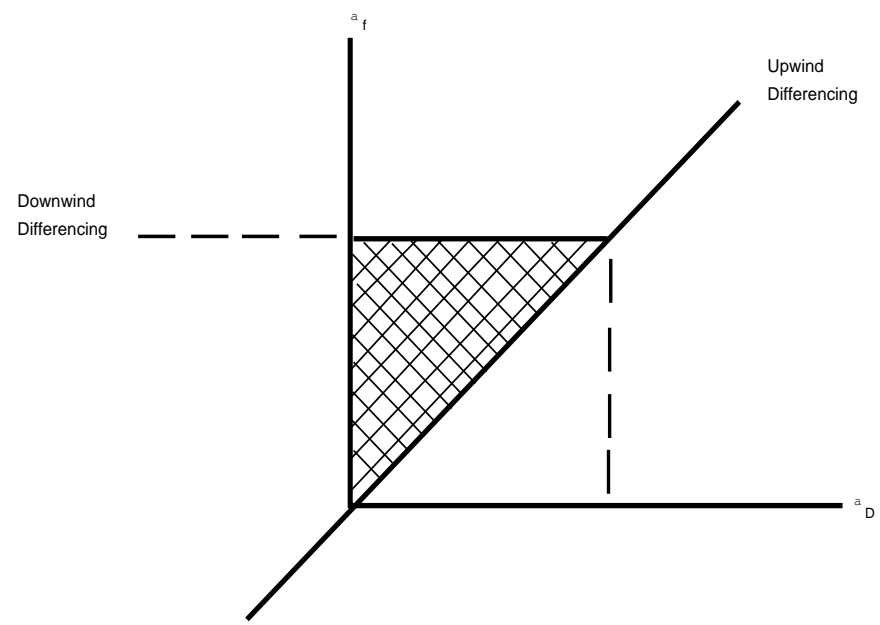

Figure 3.2: Normalised variable diagram with $\mathrm{CBC}$

The mathematical formulation of the $\mathrm{CBC}$ for implicit calculations is

$\begin{cases}\widetilde{\alpha_{f}}=\widetilde{\alpha_{D}} & \text { for } \widetilde{\alpha_{D}}<0 \quad \text { or } \quad \widetilde{\alpha_{D}}>1 \\ \widetilde{\alpha_{D}} \leq \widetilde{\alpha_{f}} \leq 1, & \text { for } 0 \leq \widetilde{\alpha_{D}} \leq 1\end{cases}$

This only preserves local boundedness for implicit flow calculations, and it was shown that CBC for explicit flow calculations can be derived. The explicit $\mathrm{CBC}$ are based on the cell CourantFriederich-Lewis (CFL) number, which is defined as

$C_{D}=\frac{\triangle t F_{\text {cell }}}{\Omega_{D}}$

where $\delta t$ is the time increment, $F_{\text {cell }}$ is the toatl flux out of the cell (considered positive) and $\Omega_{D}$ is the total volume of the donor cell. $C_{D}$ is the cell CFL number. The CBC for explicit calculations, for multidimensional flow, are then defined as

$$
\begin{cases}\widetilde{\alpha_{f}}=\widetilde{\alpha_{D}} & \text { for } \widetilde{\alpha_{D}}<0 \quad \text { or } \quad \widetilde{\alpha_{D}}>1 \\ \widetilde{\alpha_{D}} \leq \widetilde{\alpha_{f}} \leq\left\{1, \frac{\widetilde{\alpha_{D}}}{C_{D}}\right\}, & \text { for } 0 \leq \widetilde{\alpha_{D}} \leq 1\end{cases}
$$


This boundedness criterion in shown in Fig 3.3, and it is valid for both 1-D, 2-D and 3-D calculations. For $1-\mathrm{D}, C_{D}$ reduces to $C_{f}$, which is the face CFL number. The upper limit for this new CBC corresponds to the Hyper-C differencing scheme. All schemes based on normalised variables use the upwind value when $\widetilde{\alpha_{D}}<0$ or $\widetilde{\alpha_{D}}>1$. For values $0 \leq \widetilde{\alpha_{D}} \leq 1$, the resulting normalised face volume fraction $\widetilde{\alpha_{f}}$ with the schemes is shown in Table 3.1 The Hyper-C scheme

Table 3.1: Volume fraction schemes $0 \leq \widetilde{\alpha}_{D} \leq 1$.

\begin{tabular}{|c|c|}
\hline Scheme & $\widetilde{\alpha}_{f}$ \\
\hline Hyper-C & $\operatorname{Min}\left\{1, \frac{\widehat{\alpha_{D}}}{C_{D}}\right\}$ \\
\hline $\begin{array}{l}\text { Ultimate quickest } \\
\text { CICSAM }\end{array}$ & $\begin{array}{l}\operatorname{Min}\left\{\frac{8 C_{D} \alpha_{D}+\left(1-C_{D}\right)\left(6 \widetilde{\alpha}_{D}\right)+3}{8}, \widetilde{\alpha}_{f, \text { Hyper }-C}\right\} \\
\gamma_{f} \widetilde{\alpha}_{f, \text { Hyper }-C}+\left(1-\gamma_{f}\right) \widetilde{\alpha}_{f, U Q}\end{array}$ \\
\hline HRIC & $\begin{cases}2 \widetilde{\alpha}_{f}, & \widetilde{\alpha}_{D} \leq 0.5 \\
1, & \widetilde{\alpha}_{D}>0.5\end{cases}$ \\
\hline
\end{tabular}

is identical to the downwind boundary of the $\mathrm{CBC}$ for explicit calculations and thus very compressive, which means that the scheme will always keep the interface very sharp. The Ultimate quickest scheme is derived form the QUICK upwind scheme, which is diffusive, and thus makes the interface extend over many cells. The CICSAM consists of a blend of the Hyper-C scheme and the Ultimate quickest scheme using a weighting factor $\gamma_{f}$, which depends on the orientation of the interface with respect to the cell face and is defined as

$\gamma_{f} \frac{\cos \left(2 \theta_{f}\right)+1}{2}$

where

$\theta_{f}=\operatorname{arcos}\left|\frac{(\nabla \alpha)_{D} \cdot d_{f}}{\mid \nabla \alpha)_{D}|| d_{f} \mid}\right|$

In Fig. 3.4 the switching function is shown as a function of the angle between the interface and the face normal $(\theta) \cdot(\nabla \alpha)_{D}$ is the gradient of the volume fraction field and $d_{f}$ is the face normal see Fig. 3.1. In the HRIC scheme, a correction for the interface orientation and for the CFL number is also made. The interface correction, like for the CICSAM scheme, is according to the angle between the interface and the face normal $\theta$ and interpolates between the upwind and downwind values Fig.3.4.

$\widetilde{\alpha}_{f}^{*}=\sqrt{\cos \theta} \widetilde{\alpha}_{f}+(1-\sqrt{\cos \theta}) \widetilde{\alpha}_{D}$

where the upwind value is $\widetilde{\alpha}_{D}$, the downwind value is given in 3.1 and the switching function is $f_{\text {switch }}=\sqrt{(\cos \theta)}$. The HRIC scheme takes the CFL number into account according to

$\widetilde{\alpha}_{f}^{* *} \begin{cases}\widetilde{\alpha}_{f}^{*}, & \text { if } C_{D}<0.3 \\ \widetilde{\alpha}_{D}, & \text { if } C_{D}>0.7 \\ \widetilde{\alpha}_{D}+\left(\widetilde{\alpha}_{f}^{*}-\widetilde{\alpha}_{D}\right) \frac{0.7-C_{D}}{0.4}, & \text { otherwise }\end{cases}$ 
and the resulting value is $\widetilde{\alpha}_{f}^{* *}$. The normalised variable diagrams of all four schemes are shown in Fig. 3.5. The result from the interface capturing schemes is then normalised face volume fraction, from which the actual face volume fraction can be calculated:

$\alpha_{f}=\widetilde{\alpha}_{f} \alpha_{A}+\left(1-\widetilde{\alpha}_{f}\right) \alpha_{U}$

this can be rewritten as

$\alpha_{f}=\beta_{f} \alpha_{A}+\left(1-\beta_{f}\right) \alpha_{D}$

where

$\beta_{f}=\frac{\widetilde{\alpha}_{f}-\widetilde{\alpha}_{D}}{1-\widetilde{\alpha}_{D}}$

The schemes described here are not fully bounded, meaning that the resulting $\alpha$ values might yield $\alpha^{t+\delta t}<0$ or $\alpha^{t+\delta t}>1$. The original VOF method use a filtering technique where the unbounded volume fraction values were rest to either 0 or 1 after each update. It was assumed that the errors introduced here would cancel out.

The CICSAM scheme adopts a more consistent approach where the magnitude of the unboundedness is used to either upwind or downwind the scheme more, depending on the nature of the unboundedness. If a cell is filled beyond a value of 1 the scheme corrects the predicted inflow, so that the resulting value is bounded $(=1)$, and similarly for resulting values below 0 . This approach is labeled the corrector step and full description is given in (Ubbink 1997)

\subsection{VOF Cleaning Routine}

As described in chapter 2, the mass and momentum equations are only solved for the fluid water phase, and the interaction between air and fluid is neglected, therefore velocity and pressure in void cells are reset to zero after each time step. However, in order to be able to find values at cell faces for cells in the free surface region, an extrapolation scheme is applied where velocity and pressure from full cells $(\alpha>0.5)$ are extrapolated to surface cells $(\alpha<0.5)$. This requires a sharp interface where the free surface is located in a single cell in the transition from full to void cells, in order to be able to track cells in the surface region. Therefore pressure and velocity are not computed for cells outside the first layer of surface cells. If these cells still contain a small $\alpha$ value, even after the boundedness schemes in the corrector step, the value is cleaned i.e. rest to 0 . The small step is performed for cells in the fluid region where a cell with $\alpha<1$ which is not next to a surface cell will be reset to 1 . This cleaning routine is performed in order to avoid having cells in the computational domain which have a non-zero $\alpha$ value, but are inactive in the sense that the mass and momentum equations are not solved for the cell. The cleaning routine will only have an insignificant effect on the total conservation of the $\alpha$ field, except in cases where large fluid detachment sand overturning waves are very extensive. 


\section{Chapter 4 Summary of the Results}

In the following chapter results performed with the NS3 model for two sea states and analysis of irregular waves for different levels of run-up heights are presented. The laboratory experiments conducted at the large wave flume were the start up of this study, where many tests with different sea states were carried out. The NS3 model has proved to be accurate and cost effective means of analyzing the wave run-up around the circular cylinder. Comparisons between numerical and experimental data with two sea states were performed. Finally the run-up for irregular waves is analyzed and an empirical run-up formula is derived.

\subsection{Experimental Model}

Fig. 4.1 provides a schematic plan of the wave flume in which the experimental study was undertaken. This facility, which is located at Forschungszentrum Küste (FZK) in Hannover, Germany, has a length of $309 \mathrm{~m}, 7 \mathrm{~m}$ depth and $5 \mathrm{~m}$ wide. Waves were generated by a piston wave maker placed at the upstream end of the wave flume and a region to avoid reflection waves was installed at the downstream end of the wave flume to act as a passive wave absorber.

A steel cylinder was located at $111 \mathrm{~m}$ from the wave maker, a sand bed was installed 51 $\mathrm{m}$ away from the cylinder with a height of $1 \mathrm{~m}$. In order to measure accurately the process of evolution of different sea states, 32 wave gauges were arranged down the length of the channel. The position of each wave gauges is specified in Table 4.1. Experimental data collected from three of the surface elevation gauges are considered in this study as indicated in Fig. 4.1. The position at wave gauge 12 is located $111 \mathrm{~m}$ down the wave channel from the wave maker. Fig. 4.2 shows a sample of the wave elevation collected at the wave tank. Details of the experimental procedure are found in appendix.

\subsubsection{Wave conditions}

At the first stage of this study, waves were designed and generated in the wave flume. Regular, irregular and freak waves were considered in this experiment. Previous publications (Hallermeier and Galvin 1972), (Buchner and Veldman 2001), (Christensen 2007), (Christensen 2008) have shown comparison between laboratory and theoretical predictions based on linear and high-order wave theory. However, no one has yet shown the comparison with data from large scale results, subsequently, there is a limited amount of published data available to study scale effects. Table 4.2 shows the conditions for regular and focused waves. It has chosen those to validate with the results generated from the NS3 model. Table 4.3 shows the conditions for the irregular sea state, which are used to analyzed with the predicted run-up formula. 


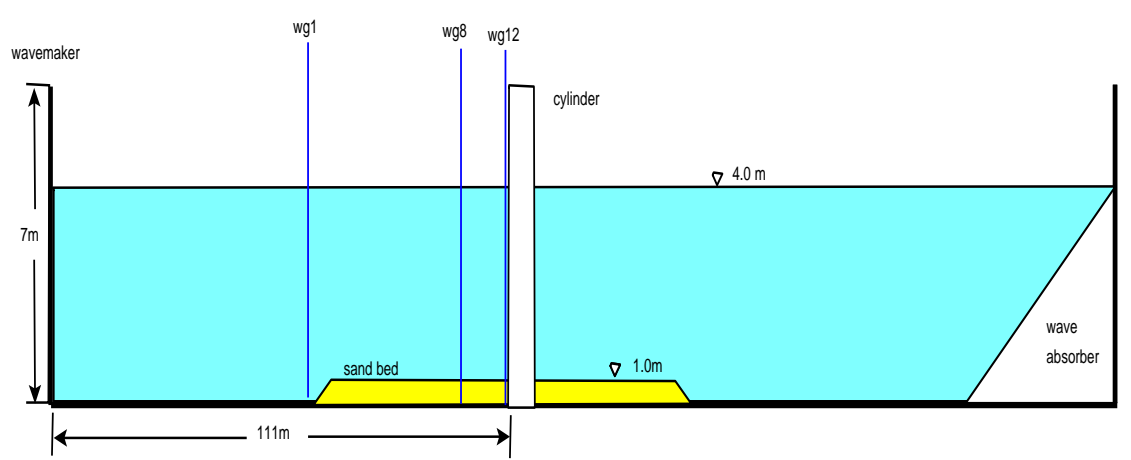

Figure 4.1: Sketch of the wave tank

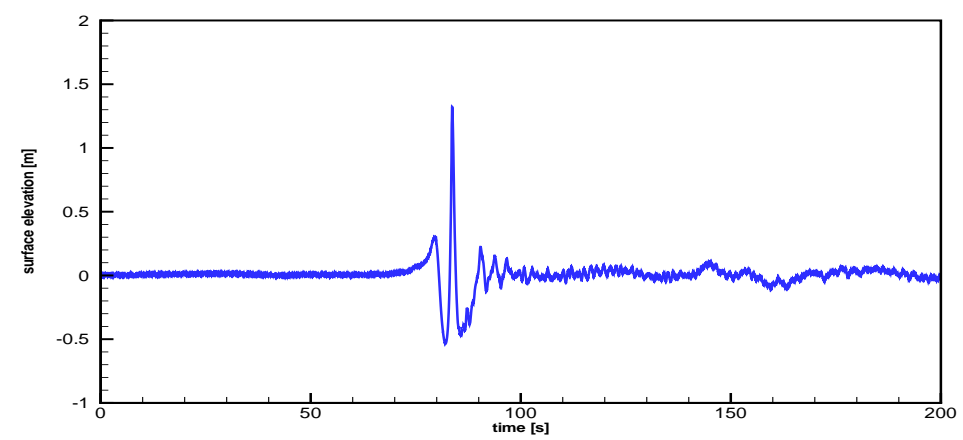

Figure 4.2: Time series of the wave elevation of freak wave

Fig 4.4 shows the focused wave elevation, the amplitude and the phase of the Fourier components, which are extracted by applying a fast Fourier transform (FFT). 


\begin{tabular}{|c|c|c|}
\hline Channel & Description & Distance $[\mathrm{m}]$ \\
\hline 1 & WG1 & 50 \\
\hline 2 & WG2 & 51.9 \\
\hline 3 & WG3 & 55.2 \\
\hline 4 & WG4 & 60 \\
\hline 5 & WG5 & 70 \\
\hline 6 & WG6 & 80 \\
\hline 7 & WG7 & 90 \\
\hline 8 & WG8 & 100 \\
\hline 9 & WG9 & 103.5 \\
\hline 10 & WG10 & 107 \\
\hline 11 & WG11 & 110 \\
\hline 12 & WG12 & 111.02 \\
\hline 13 & WG13 & 112.94 \\
\hline 14 & WG14 & 120 \\
\hline 15 & WG15 & 130 \\
\hline
\end{tabular}

\begin{tabular}{|c|c|c|}
\hline Channel & Description & Distance [m] \\
\hline 16 & WG16 & 140 \\
\hline 17 & WG17 & 150 \\
\hline 18 & WG18 & 160 \\
\hline 19 & WG19 & 161.9 \\
\hline 20 & WG20 & 165.2 \\
\hline 21 & WG21 & 170 \\
\hline 22 & WG22 & 180 \\
\hline 23 & WG23 & 0 degrees \\
\hline 24 & WG24 & 30 degrees \\
\hline 25 & WG25 & 60 degrees \\
\hline 26 & WG26 & 90 degrees \\
\hline 27 & WG27 & 120 degrees \\
\hline 28 & WG28 & 150 degrees \\
\hline 29 & WG29 & 180 degrees \\
\hline 31 & Paddle input & 0 \\
\hline
\end{tabular}

Table 4.1: Distances from wave generator to the instruments.

Table 4.2: Experimental conditions for validation with NS3 model(model scale).

\begin{tabular}{c|ccc|ccc}
\hline \multicolumn{4}{c|}{ At the paddle } & \multicolumn{3}{c}{ At the pile } \\
\hline \hline Test & $h[\mathrm{~m}]$ & $T[s]$ & $H[\mathrm{~m}]$ & $h[\mathrm{~m}]$ & $T[s]$ & $H[\mathrm{~m}]$ \\
\hline Regular wave & 4 & 6.0 & 1.0 & 3 & 6.0 & 0.9 \\
Focused wave & 4 & 4.6 & 1.03 & 3 & 4.6 & 1.15 \\
\hline
\end{tabular}

Table 4.3: Experimental conditions for irregular sea state (model scale).

\begin{tabular}{c|cccc|cccccc}
\hline \multicolumn{5}{c|}{ At the paddle } & \multicolumn{6}{c}{ At the pile } \\
\hline \hline Test & $h[\mathrm{~m}]$ & $T_{p}[s]$ & $H_{m 0}[\mathrm{~m}]$ & $s_{0 p}$ & $h[\mathrm{~m}]$ & $T_{p}$ & $H_{m 0}$ & $H_{\max }$ & $H_{2 \%}$ & $s_{0 p}$ \\
\hline 1 & 4 & 4.5 & 1.05 & 0.033 & 3 & 4.7 & 0.91 & 1.41 & 1.16 & 0.026 \\
2 & 4 & 5.9 & 1.10 & 0.020 & 3 & 6.0 & 1.00 & 1.66 & 1.23 & 0.018 \\
3 & 3 & 5.9 & 1.10 & 0.020 & 2 & 6.0 & 0.81 & 1.08 & 0.96 & 0.014 \\
\hline
\end{tabular}




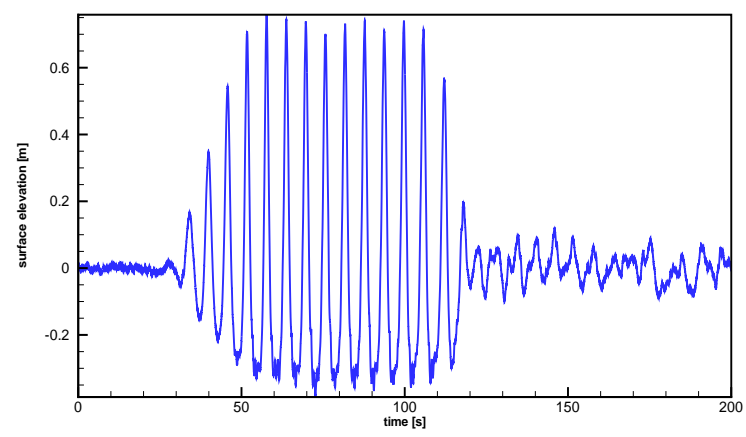

(a) Completed wave elevation, information obtained from wave gauge 12

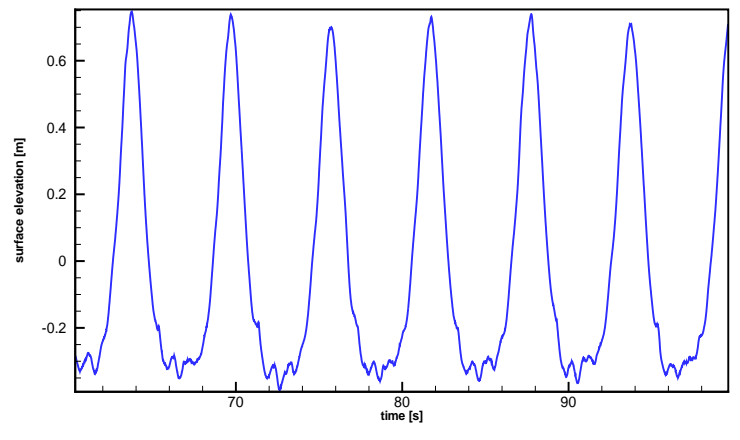

(b) Selected wave elevation, information obtained from wave gauge 12

Figure 4.3: Laboratory measured wave $T=6.0 \mathrm{~s} H=1.0 \mathrm{~m}$ 

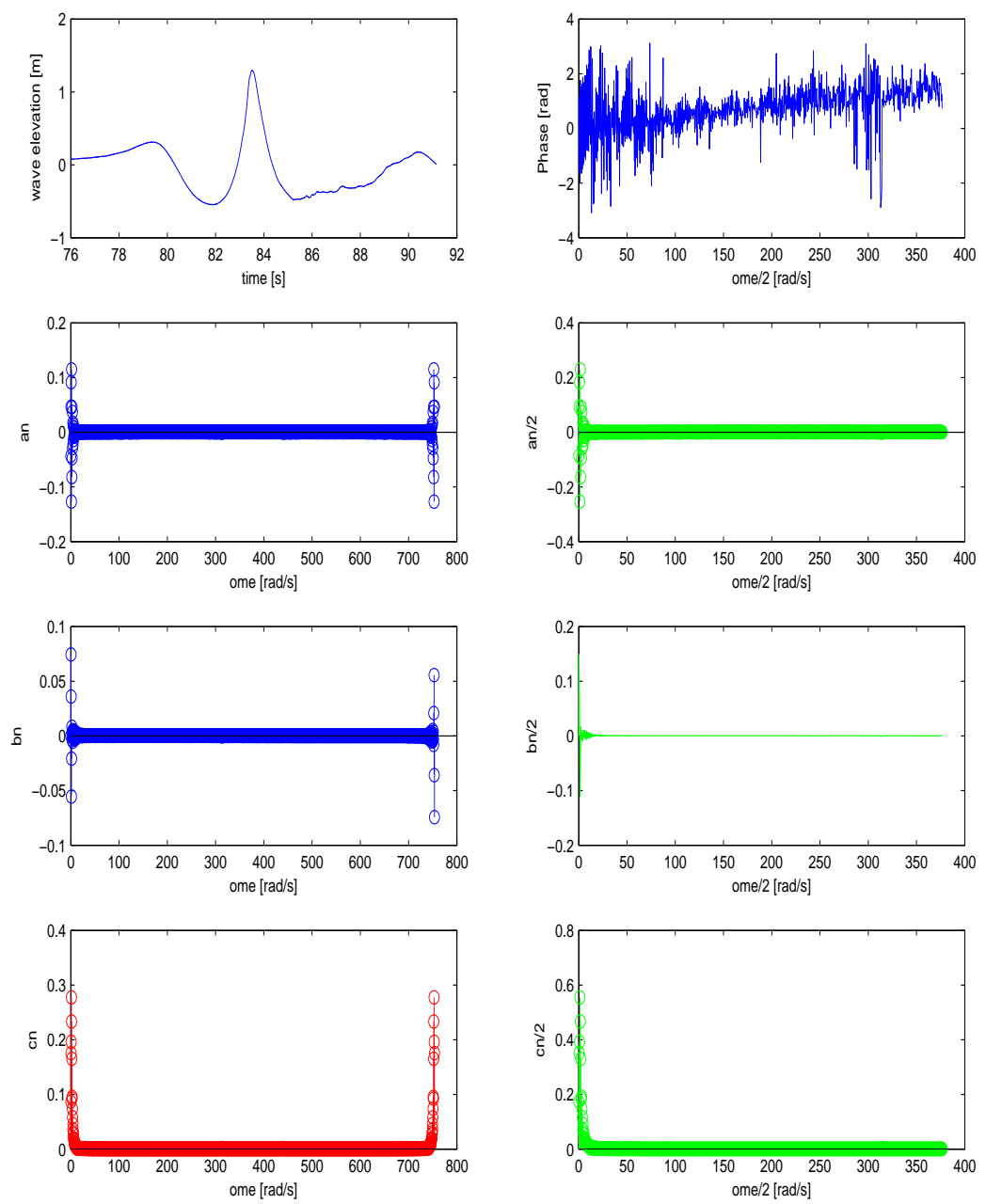

Figure 4.4: Laboratory wave elevation and Fourier coefficients obtained using FFT for focused waves. 


\subsection{NS3 model}

The routine and the input file to perform simulations are detailed in the following section.

\subsubsection{NS3 set-up}

This section outlines how to make NS3 run with incident waves, the results of the calculations are the time series of the surface elevation. Three main steps are detailed in the following
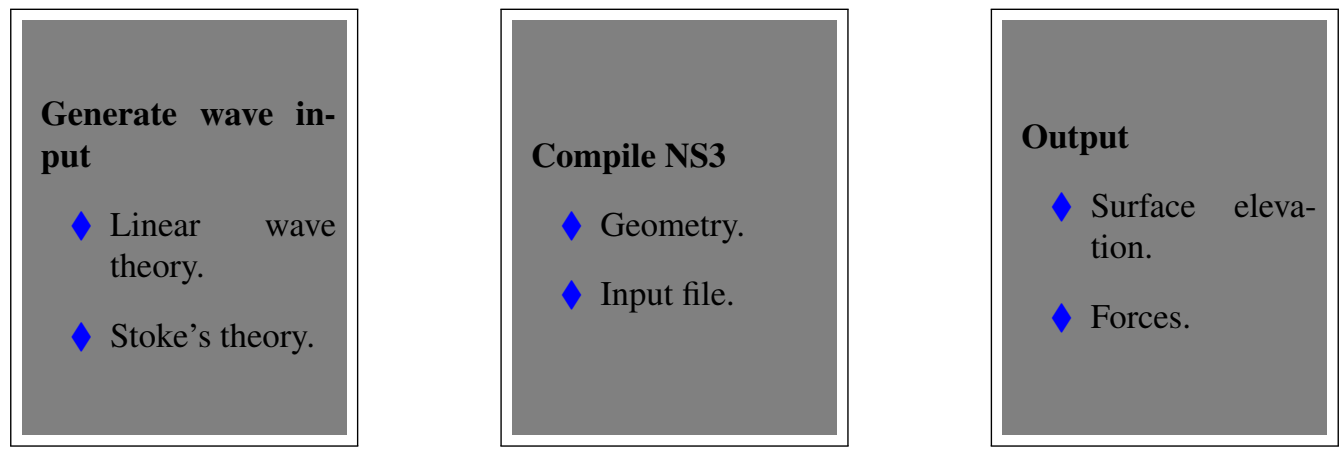

the input file is presented below highlighted in yellow to show the main parameters used in the simulations. It should be mentioned that several attempts were carried out pursuing reasonable results, between them are configuration of grids, CFL's number, time lag, sponge layer.

\section{Listing 4.1: A commented version of the input file}

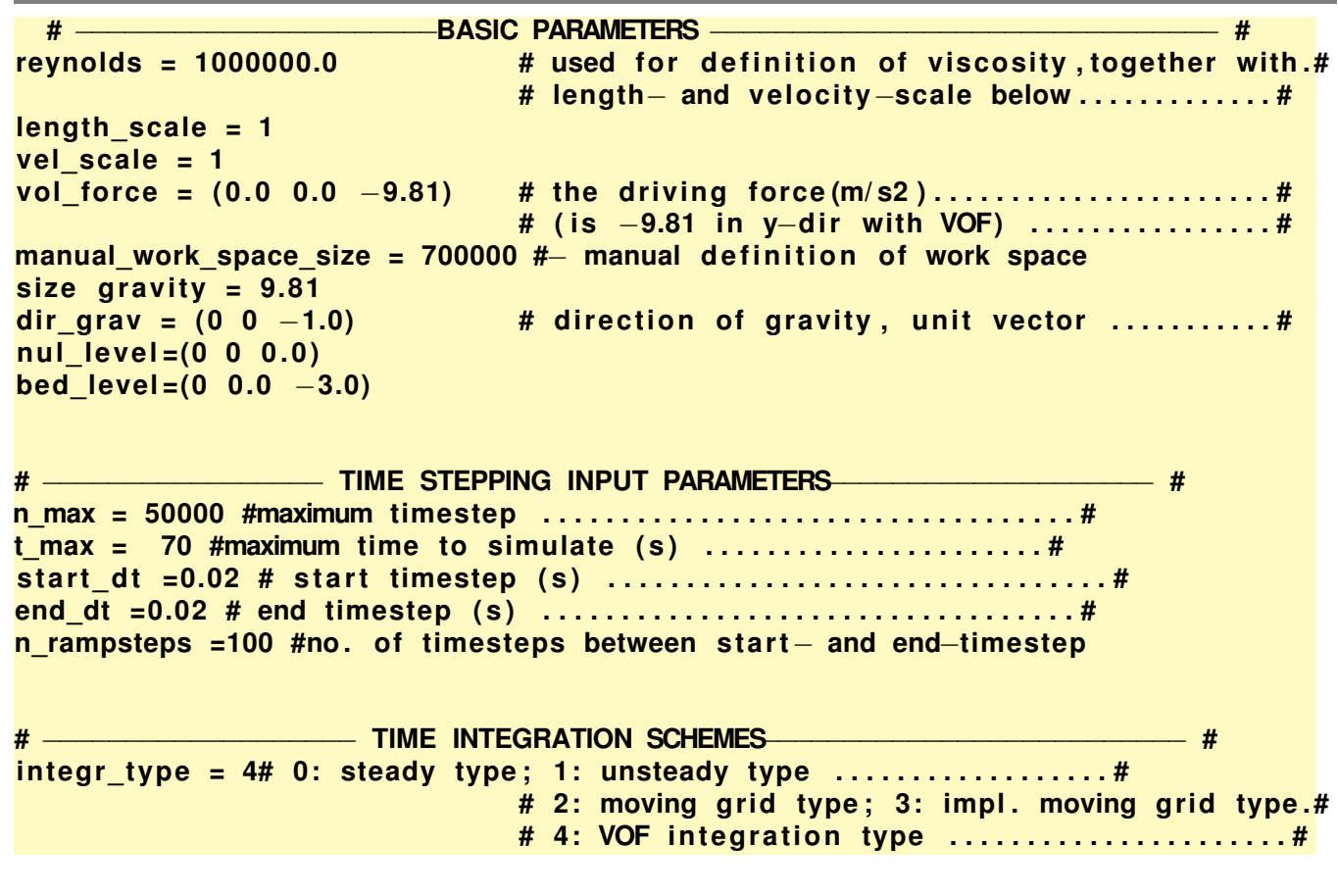




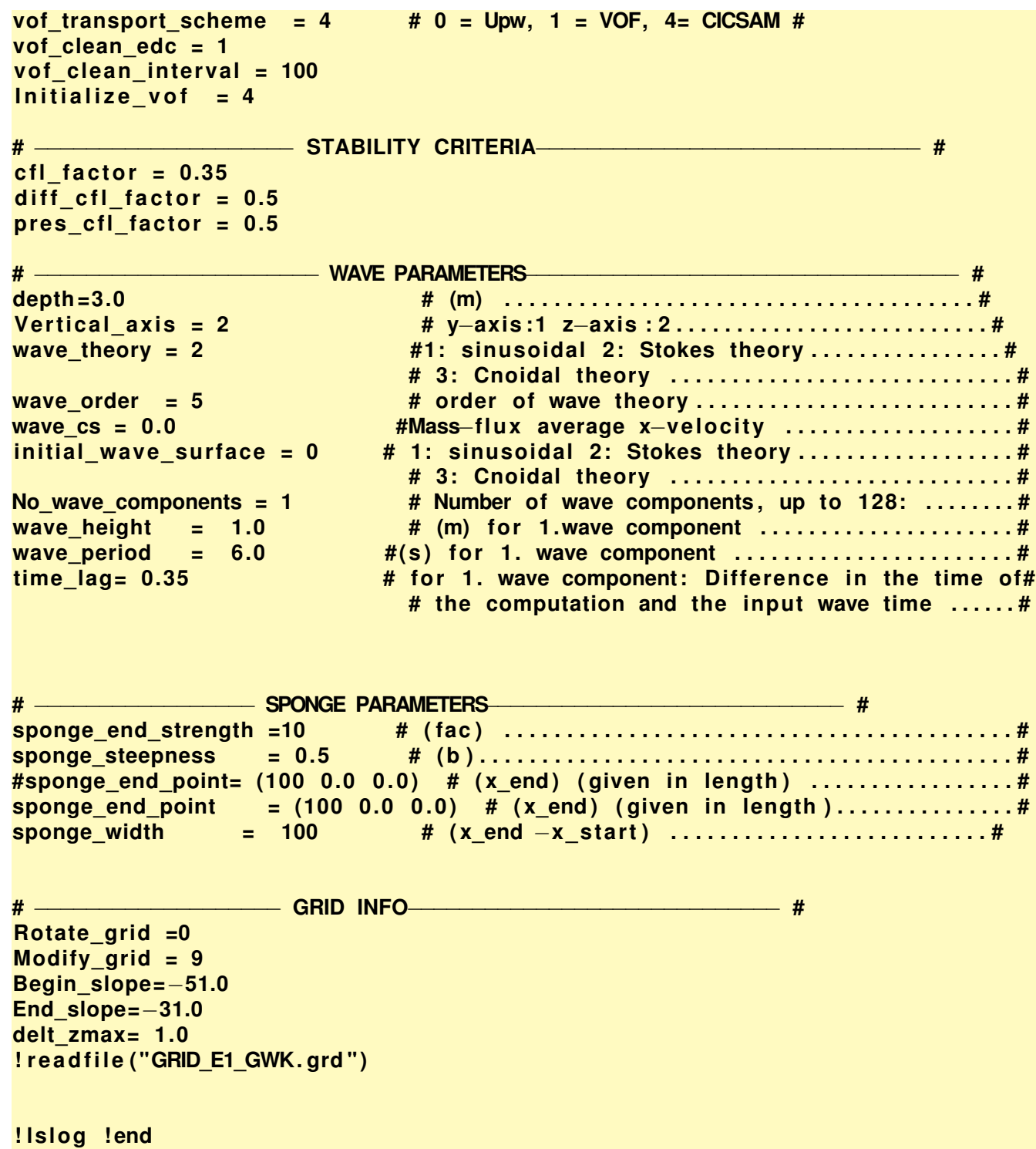

! Islog !end

The wave input is generated in different methods in a numerical domain. In the next section we described some methods and address the pro and cos of those.

\subsubsection{Generation of waves: Numerical procedure}

To calculate the run-up height on structures the wave generation in a numerical wave tank is essential. When waves are present in the numerical domain the entirely phenomenon can be studied in detail.

There are three different possibilities to model the wave generation in a numerical wave 
tank, but it needs to be exact to find good agreement after compare with any experimental tests. The first option is imitate the motion of the wave maker from the experiments, thereby while the flap is moving the incident wave is generating. The main issue with this method is the distance from the wave maker to the structure. In a numerical domain this distance will demand large time of computations added to lost of accuracy especially around the structure. The second option is generate the wave at the inflow boundary of the numerical domain using diverse wave theories. This method seems very useful to imitate the waves from the experiments, but precaution when the wave-structure interacts needs to be into account. The third option is used the measurements of the wave elevation close to the structure to prescribe the wave at the inflow boundary at the same distance from the structure. The measured wave elevation can be decomposed using FFT technique and the components can be superposed at the inflow boundary.

\subsection{NS3 configuration}

The computational domain is shown in Fig.4.5, the dimensions of the numerical flume is chosen to be similar to the physical wave flume where the experiments were carried out. More details about NS3 set up for this study are described in Appendix 4. Fig.4.5 shows the numerical wave tank from above and from the side, which is divided in 12 blocks. The refinement of the grid ensured high accuracy on the results, in addition to the grid sensitivity, the Courant number, CFL and thus of the time step has also been taken into account.

\subsection{CFD Outcomes}

Results obtained from the numerical calculations are shown in this section. Table 4.2 shows the sea conditions for the validation study. The wave surface elevation from the experiments is compared to results from numerical simulations which are based on potential flow theory and the comparison is expected to be reasonable.

Fig. 4.6 shows the results for the case of regular waves. Note that it has been plotted for $49 s<$ time $<110 s$ only and for the region close to the cylinder. It can seen the excellent agreement with the experimental results.

Now that we know NS3 can obtained results quite accurately as the previous case has shown, it is time to go one step further and investigate the focused wave case, which contains non-linear waves. For this case the mesh layout has been changed, the grid spacing outside the region of the cylinder was stretched in both and horizontal directions, leaving relatively large cells in the area of less importance, given more cells to the grid region near the cylinder in order to capture the run-up height with detail. The Courant number CFL has been changed for keeping stability of the calculations. The input file was modified at the wave parameters sections, defining several wave components as wave height, wave period and time lag. It has been specified 9 components in this case.

Fig. 4.7 shows the wave surface elevation close the cylinder. The comparison with the experiments is very good, the amplitude of the simulation is a bit smaller than in the experiments, which can be consequence of the long numerical domain, also the dissipation of energy could be added as a key issue. Further, the results show that NS3 is capable to reproduce non-linear phenomenons but does not always reproduce the height of the wave exactly. 

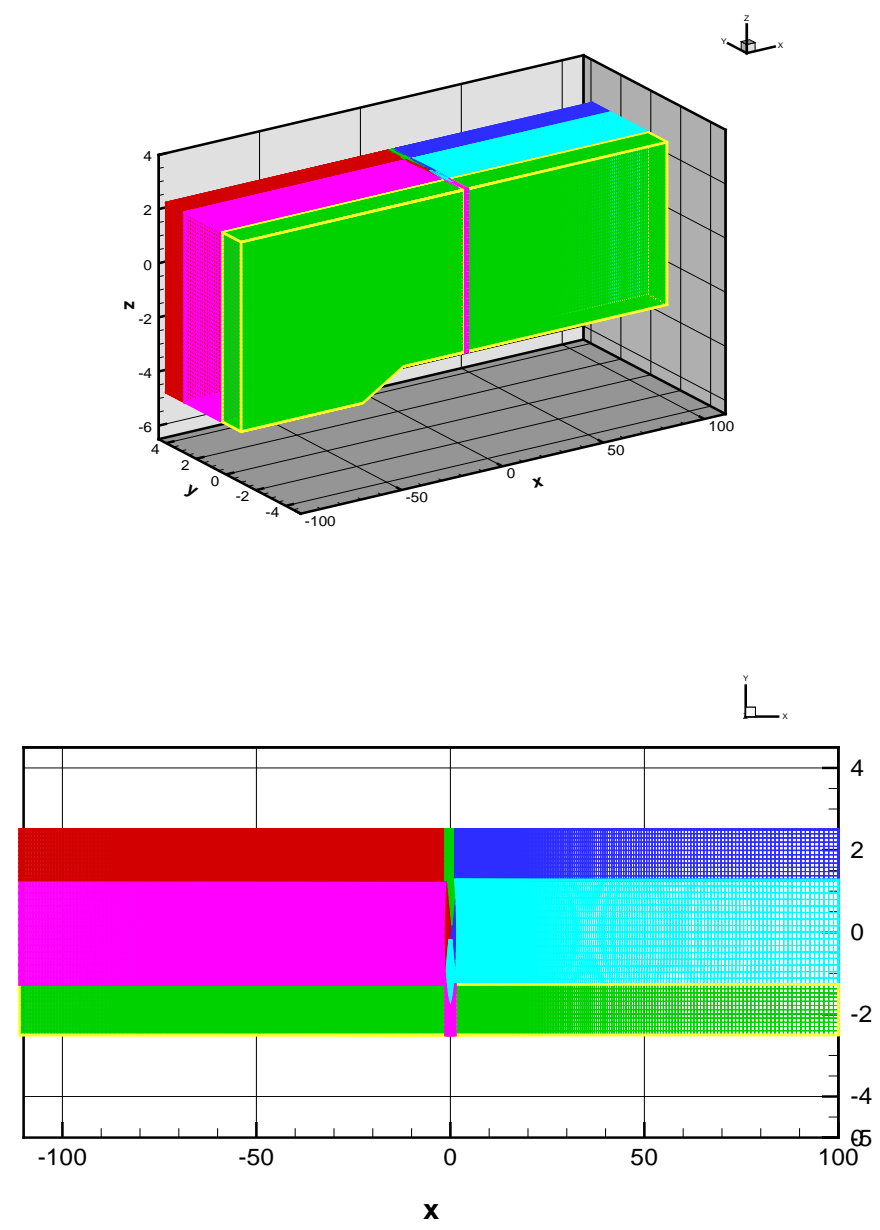

Figure 4.5: NS3 grid built

In both cases the results obtained are very reliable. It can improve more by the use of refining mesh. Unfortunately, this is not possible because of the large time of computations. 

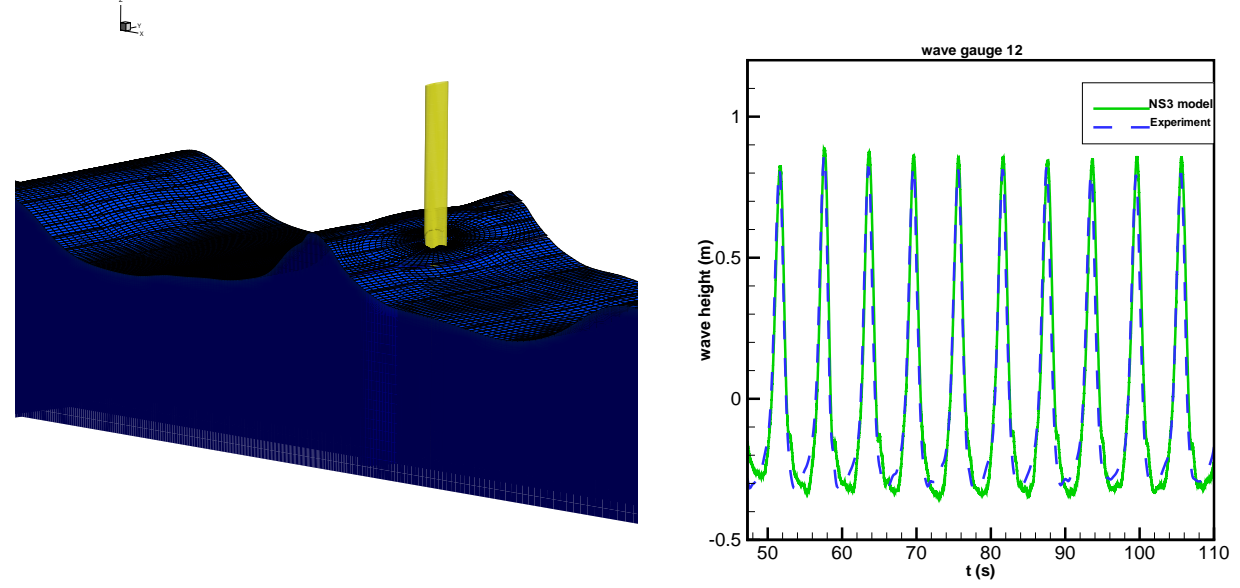

Figure 4.6: Wave run-up:Regular waves
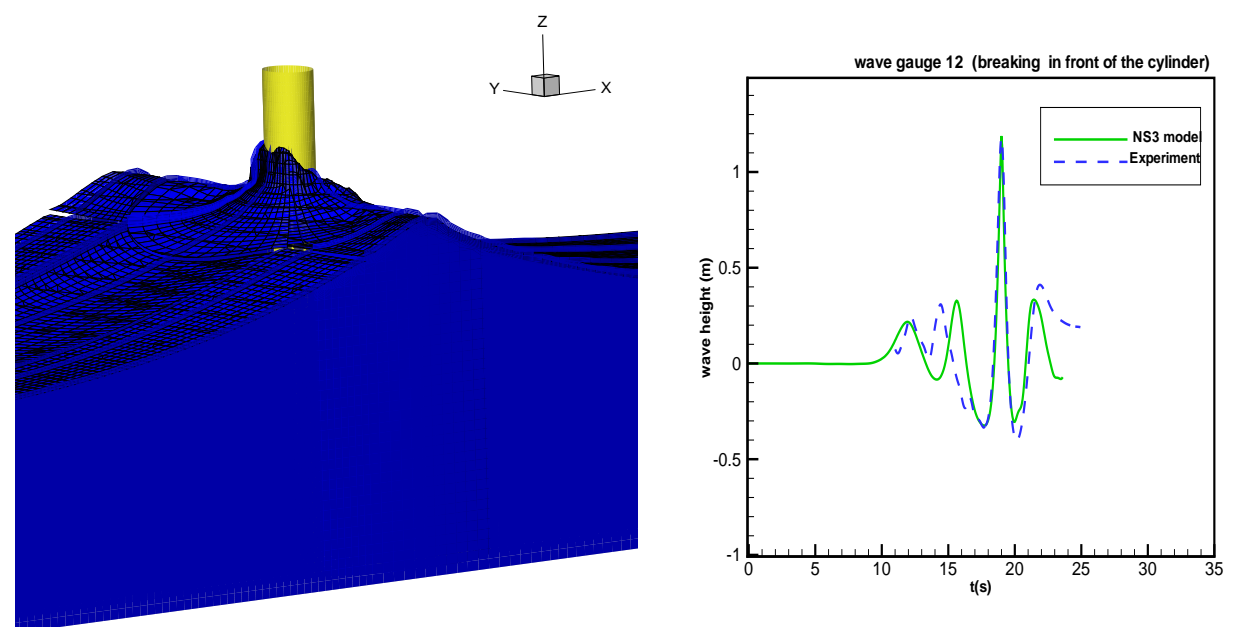

Figure 4.7: Wave run-up:Focused waves 


\subsection{Wave run-up: Experimental results}

In this section some experimental results concerning the circular cylinder are discussed. Table 4.3 lists the conditions for the irregular sea state. The measured results were obtained from three wave gauges located at the side wall. It has been used the Wavelab software developed by Aalborg University to get the incident surface elevation in the time domain.

Three levels were found in each test given significant run-up height

$\checkmark$ Level A: Level for green water run-up (thick layer).

- Level B: Level for thin layer of water and air mixture, water layer which is not longer attached to the surface of the pile or high spray concentration.

Level C: Level for maximum spray. When the spray went higher than the maximum level which was marked on the pile, this value was estimated as good as possible

To calculate the run-up height the prediction formula Eq.(4.1) based on velocity head stagnation theory was used.

$$
R_{u, \max }=\eta_{\max }+m \frac{u_{\max }^{2}}{2 g} \quad R_{u, 2 \%}=\eta_{2 \%}+m \frac{u_{2 \%}^{2}}{2 g}
$$

To obtain the $m$ factor in Eq.(4.1), stream function theory was used to calculate the maximum wave crest $\left(\eta_{\max }\right)$ and the particle velocity $(u)$ on the top of the crest. Further details of this procedure can be found in Appendix C.

(Lykke Andersen T. 2010) demonstrated that this approach gave a good fit to small scale laboratory data therefore it is used in this study for the three levels of run-up height by the used of the predicted formula Eq.(4.1) to calculate the maximum and the $2 \%$ run-up height.

The following expression has been fitted to the results

$\checkmark$ Level A

$m= \begin{cases}-66.667 s_{0 p}+5.33 & \text { for } s_{0 p}<0.035 \\ 3 & \text { for } s_{0 p}>0.035\end{cases}$

Level B

$m= \begin{cases}-93.333 s_{0 p}+7.47 & \text { for } s_{0 p}<0.035 \\ 4.2 & \text { for } s_{0 p}>0.035\end{cases}$

Level C

$m= \begin{cases}-200 s_{0 p}+16 & \text { for } s_{0 p}<0.035 \\ 9 & \text { for } s_{0 p}>0.035\end{cases}$ 

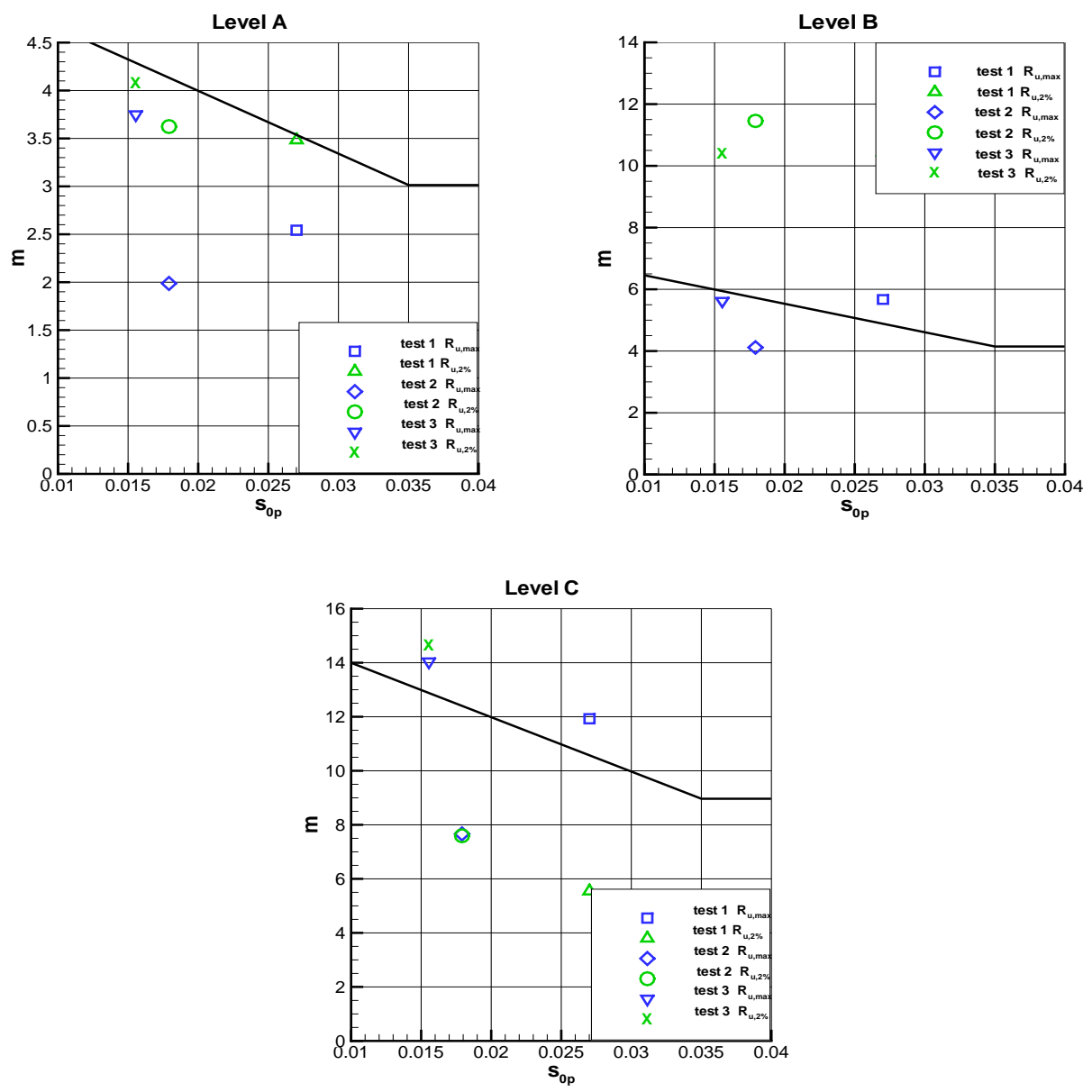

Figure 4.8: Proposed adjustment $m$ factor plotted against deep water wave steepness. Wave kinematics are computed by stream function theory using $H_{\max }$ for $R_{u, \max }, H_{2 \%}$ for $R_{u, 2 \%}$ and $T_{p}$ in both cases.

Fig. (4.8) shows the results of $m$ factor versus the deep water wave steepness for the maximum and $2 \%$ run-up for the three tests selected. It is shown the data is scattered. Fig. (4.9) shows the run-up height predicted and measured by means of the Eq.(4.1). It is seen the scatter of $m$ is less important for the overall prediction method as the very high $m$ values for level B are for cases with relative low velocity head compare to $\eta_{\max }$. It can be seen good agreement with the run-up formula for level $\mathrm{A}$ and $\mathrm{B}$ while level $\mathrm{C}$ is more scattered because the formation of the spray. It should be mentioned that the effect scales on this experiments are not significant as they are well predicted by the methodology adopted by (Lykke Andersen T. 2010) based on the small scale tests. 

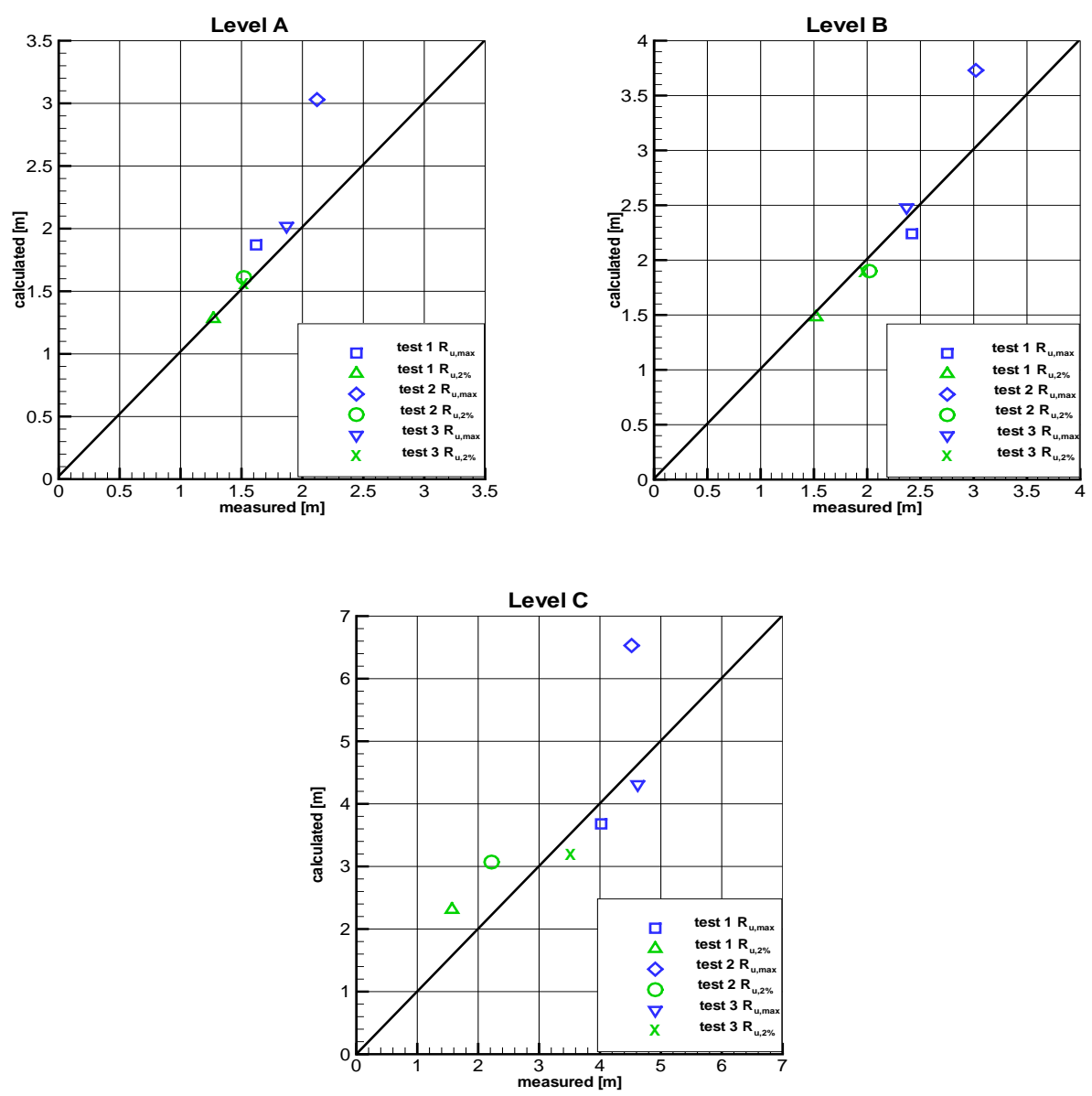

Figure 4.9: Comparison of the wave run-up predicted versus estimated, using Eqs. (4.2)-(4.4) for $2 \%$ and maximum run-up levels. 


\section{CHAPTER 5 Future work and open questions}

The wave run-up on a circular cylinder has been studied addressing verification and validation by the use of CFD codes as initial stage, then analyzing the statistical data collected from the experimental campaign by the use of Lykke's methodology. This chapter presents a summary of the important findings and original contributions to this thesis.

\subsection{Concluding Remarks}

CFD models have proven to be an invaluable tool in many areas of engineering. Many problems have been addressed by means of use of commercial models. However, some of them present less accuracy than others. To get confidence in the results provided by NS3 model. It has been started for the most simple case, upon satisfactory implementation of the simple problem, the next layer of complexity could be addressed, the problem modelled and again validated. It has been highlighted the outcomes obtained with the study of the wave run-up in regular and focused waves, which have been chosen to validate the CFD code NS3. It has seen this numerical model can predict the run-up height with good accuracy, however the larger computational time could be safe by the reduction of the numerical grid. Overall, the aim of the investigation was achieved. It should be mentioned the wave surface elevation measured at a distance far from the cylinder present very good agreement with the experimental results. The numerical model have used the initial sea bed topography instead of the reshaped one after some waves, this can be affected the wave surface elevation measures close the cylinder and small disagreements can be seen in the results presented.

NS3 has been shown robust and capable to predict the wave elevation around the cylinder with a satisfactory level, but still much effort needs to be directed to the improvement of the numerical method, such a two phase flow model, where the air is taken into consideration and in the present study was overlooked.

The main weakness observed while using NS3 model is the excessive computational run times. But this issue has been observed in all CFD codes when is used a fine mesh, a possible solution is to use coarse and medium mesh, however, accuracy in the results will be low. Finally, for the case of focused waves certain shortcomings were found when this case was simulated due to the high non-linearity of this phenomenon added to the fact the interaction of the water waves with the cylinder, was impossible to achieve high accuracy in the results. It should be mentioned that the computational run times exceed the physical run times by far, some simulations lasted over a day while a physical test lasted $10 \mathrm{~min}$, unless this problem can be overcame, physical experiments will always the best alternative over CFD simulations. 
The second part of this study addressed the large scale measurements with irregular waves. Run-up levels for green water run-up, thin layer of water air mixture and maximum spray levels were determined for individual waves. The procedure established by (Lykke Andersen T. 2010) was used to analyzed the maximum and $2 \%$ run-up and compared with experiments based on small scale, showing good agreement and not scale effects have been found in the run-up heights. Furthermore the results presented herein show that is difficult to calculate the run-up of individual waves without taking into consideration the form of the waves. 


\section{Bibliography}

Brorsen, Michael (2007). Nonlinear Waves. Aalborg University. Department of Civil Engineering, 2007. 40 p.

Buchmann, Bjarne (1999, July). Time domain modelling of run-up on offshore structures in waves and currents. Ph. D. thesis, Department of Hydrodynamics and water resources, Technical University of Denmark.

Buchmann, Ferrant P., B. and Skourup, J. (1998). Run-up on a body in waves and current, fully non-linear and finite order calculations. 13th International workshop on water waves and floating bodies 1, 9-12.

Buchmann, Skourup J., B. and Cheung, K.F. (1997). Run-up on a structure due to waves and current. In Proceeding of the Seventh International Offshore and Polar Engineering Conference.

Buchner, Fekken T. H. J., B. and Veldman, A.E.P (2001). A numerical study on wave run up on an fpso bow. In International Conference on Offshore and Arctic Engineering OMAE.

Chakrabarty, S. K. and Tam, W. A. (1975). Wave height distribution around a vertical cylinder. Journal of Waterways, Harbours and Coastal Engineering 101, 225-230.

Christensen, H. ; Hansen E. A., E. D. ; Bredmose (2005, October). Extreme wave forces and wave run-up on offshore wind-turbine foundations. In Copenhagen Offshore Wind Conference.

Christensen, Hansen E. A. Yde L. Tarp-Johansen N.J. Gravesen H. Damsgaard M. L., E.D. (2007). Wave loads on offshore wind turbine foundations in shallow water. engineering models vs. refined flow modelling. European Offshore Wind 1.

Christensen, Mortensen S.B. Nielsen A.W Jacobsen V., E.D. (2008, June 15-20). Numerical modelling of wave run-up on a wind turbine foundation. In Proceedings of the ASME 27th International Conference on Offshore and Arctic Engineering OMAE.

De Vos, Frigaard P. De Rouck J., L. (2007). Wave run-up on cylindrical and cone shaped foundations for offshore wind turbines. Coastal Engineering 54, 17-29.

Hallermeier, R. J. and Galvin, C. J. (1972). Wave run-up on vertical cylinders. In Intl. Conf. on Coastal Engineering, Vancouver, Canada.

Harlow, F. H. and Welch, J. E. (1965). Numerical calculations of time dependent viscous incompressible flow of fluid with free surface. Physics Fluids 8(12), $2182-2189$

Hirt, C. W. and Nichols, B. D. (1981). Volume of fluid (vof) method for the dynamics of free boundaries. Journal of Computational Physics 39, 201 -225.

Isaacson, M. de St Q. and Cheung, K.F. (1993). Time domain solution for wave current interaction with a two dimensional body. Applied Ocean Research 15(1), 39-52. 
Kawamura, Mayer S. Garapon A., T. and Sørensen, L. (1997). A curvilinear multiblock solver for the unsteady incompressible navier -stokes equations. Technical report, International Research Center for Computational Hydrodynamics, Denmark.

Kawamura, Mayer S. Garapon A., T. and Sørensen, L. (2002). Large eddy simulation of a flow past a free surface piercing circular cylinder. Journal of Fluids Engineering, 124.

Kim, C. H. (2008). Nonlinear Waves and Offshore Structures. World Scientific.

Kleefsman, Fekken G. Veldman A.E.P. Iwanowski B.-Buchner B., K.M.T. (2005a). A volume of fluid based simulation methodfor wave impact problems. Journal of Computational Physics 206, 363-393.

Kleefsman, Theresa (2005b, November). Water Impact Loading on Offshore Structure. Ph. D. thesis, University of Groningen.

Kriebel, DL (1990). Nonlinear wave diffraction by vertical circular cylinder. part 1: Diffraction theory. Ocean Engineering 17, 345-377.

Kriebel, DL (1992). Non-linear wave interaction with a vertical circular cylinder. part ii: wave run-up. Ocean Engineering 19(1), 75-99.

Leonard, B. P. (1991). The ultimate conservative difference scheme applied to unsteady one dimensional advection. Computer Methods in Applied Mechanics and Engineering 88, 17-74.

Lykke Andersen T., Damsgaard M.L. De Vos L., Frigaard P. (2010). Wave run-up on slender piles in design conditions-model tests and design rules for offshore wind. Coastal Engineering 58, 281-289.

Martin, Easson W. J. Bruce T., A. J. (2001). Run-up on columns in steep, deep water regular waves. Journal of Waterway, Port, Coastal and Ocean Engineering. 127, 26-32.

Mayer, Garapon A., S. and Sørensen, L. S. (1998). A fractional step method for unsteady free surface flow with applications to non linear wave dynamics. International Journal for Numerical Methods in Fluids 28(2), $293-315$.

Monaghan, J.J. (1992). Smoothed particle hydrodynamics. Annu. Rev. Astron. 30, 543-574.

Morris-Thomas, M.T and Thiagarajan, K.P. (2004). The run-up on a cylinder in progressive surface gravity waves: Harmonic components. Appl. Ocean Res. 26, 98-113.

Morris-Thomas, Repalle N., M. T. and Thiagarajan, K. P. (2007). Cfd simulation of wave run-up on a spar cylinder. In 16th Australasian Fluid Mechanics Conference.

Muzaferija, Peric M. Sames P., S. and Schellin, T. (1998). A two fluid navier-stokes solver to simulate water entry. In Twenty Second Symposium on Naval Hydrodynamics, pp. 638-651.

Myrhaug, D. and Holmedal, L. E. (2010). wave run-up on slender circular cylindrical foundations for offshore wind turbines in nonlinear random waves. Coastal Engng 57(6), 567-574.

Myrhaug, Hesten P. Holmedal L. E., D. (2011). A stochastic method for wave run-up on slender circular cylinders due to long-crested and short-crested non-linear random waves. Journal of Engineering for the Maritime Environment 225, 350-360.

Niedzwecki, J. M. and Duggal, S. D. (1992). Wave run-up and forces on cylinders in regular and random waves. Journal of Waterway, Port, Coastal and Ocean Engineering. 118(6).

Nielsen, K.B. and Mayer, S. (2004). Numerical prediction of green water incidents. Ocean Engineering. 31, 363-399.

Nielsen, Kristian Bendix (2003, June). Numerical prediction of green water loads on ships. Ph. D. thesis, Department of Mechanical Engineering, Technical University of Denmark.

Ramirez, Frigaard P. Lykke Andersen T., J. and Christensen, E.D. (2011, June 19-24). Numerical modelling of wave run-up : regular waves. In Twenty-first International Offshore and Polar Engineering Conference : ISOPE. 
Sterndorff, M. J. (2002). Large-scale model test with wave loadings on offshore platform deck elements. In International Conference on Offshore Mechanics and Artic Engineering-OMAE-ASME.

Ubbink, O. (1997). Numerical prediction of two fluid systems with sharp interfaces. $\mathrm{Ph}$. D. thesis, University of London.

Young, D. L. (1987). An interface tracking method for a 3d eulerian hydrodynamics code. Technical Report AWRE/44/92/35.

Zang, Street R.L., Y. and Koseff, J. R. (1994). A non-staggered grid, fractional step method for the time incompressible navier-stokes equations in curvilinear coordinates. Journal of Computational Physics 114, 18-33. 


\section{APPENDIX A Fourier Transform}

Let a sample time series $x(t)$ of length $T$ be expressed in terms of infinite trigonometric function series:

$x(t)=A_{0}+\sum_{n=1}^{\infty}\left(A_{n} \cos \omega_{n} t+B_{n} \sin \omega_{n} t\right)$

where $\omega_{n}$ is the circular frequency of the $n^{\text {th }}$ harmonic term. Let $T$ be the fundamental wave period, then the frequency of fundamental harmonic is $\omega_{1}=2 \pi / T=\delta \omega$. Consequently the frequency of the $n^{\text {th }}$ harmonic term becomes $\omega_{n}=n \omega_{1}$. The coefficients of the trigonometric function series in Eq.A-1 are obtained applying the orthogonal property of trigonometric functions:

$$
\begin{array}{r}
A_{0}=\frac{1}{T} \int_{0}^{T} x(t) d t \\
A_{n}=\frac{2}{T} \int_{0}^{T} x(t) \cos \omega_{n} t d t \\
B_{n}=\frac{2}{T} \int_{0}^{T} x(t) \sin \omega_{n} t d t
\end{array}
$$

Employing FFT, one determines the above unknown coefficients numerically. The basic approach of the algorithm is briefly reviewed. First one determines the mean value from $x(t)$ and subtracts it from the original time series to make it zero-mean time series, which makes $A_{0}$. Then there remains unknowns $\left.\left.\left(A_{(} n\right), B_{(} n\right)\right)$ to be determined. The sample data points are usually determined using the computer at sample intervals; $\triangle t, 2 \triangle t, 3 \triangle t, \ldots N \triangle t$, giving $T=N \triangle t$. In the second place, the trigonometric series is expressed as a function of frequency; $\omega_{1}=\Delta \omega, \ldots, \omega_{n}=n \triangle \omega, \ldots, \omega_{\max }=(N / 2) \triangle \omega$, so that the total number of unknown coefficients $\left(A_{n}, B_{n}\right)$ may become $N$.

\section{A.1 Note for using fft and ifft in MATLAB}

Given the sample time series $x\left(t_{m}\right)$, one may determine the Fourier transform $X_{n}$ by FFT code in MATLAB. However, it should be noted that the code does not contain $\triangle t$. Likewise the inverse fast Fourier transform (IFFT) code does not contain $\triangle f . X_{n}=f f t(x)$ provides $N$ pairs of complex Fourier transform without $\triangle t$. The first $N / 2$ complex pairs are for the positive frequency while the rest of $N / 2$ pairs are for negative frequency components which are complex conjugate of the first half. These positive and conjugate components are for two sided spectrum. The negative frequency part has to be discarded when one considers one-sided spectrum. 


\section{APPENDIX B Stream Function Theory}

This section is based on (Brorsen 2007). In order to get accurate values of wavelength and wave kinematics on shallow water, $h / L<0.10$, one has to apply the so called stream function theory. This theory is based on an approximate numerical solution of the governing PDE together with the exact boundary conditions fulfilled at $z=\eta$ Because it is unnecessary to make assessments of terms and discard the small ones the theory makes no demands to $H / L$ or $h / L$. It is assumed that we have potential flow at $\bar{u}=U=0$, i.e. the wave is propagating on stagnant water. For the sake of convenience the wave is described in the $\left(x_{r}, z_{r}\right)$-system following the wave. See figure 3.1. Seen from this coordinate system the wave profile is not moving, and the corresponding flow is consequently steady. The $\left(x_{r}, z_{r}\right)$-system has the velocity $c_{r}$ compared to the stagnant water and the $(x, z)$-system fixed to the stagnant water body. So far this propagation velocity has simply been denoted $c$.

Notice that the bottom and the $(x, z)$-system are moving to the left with the velocity $c_{r}$ seen from the $\left(x_{r}, z_{r}\right)$-system. See figure 3.1. Notice that $z_{r}=z$, and in the following we will not distinguish between $z$ and $z_{r}$.

By introduction of the stream function $\psi$ defined by the equations:

$u=-\frac{\partial \psi}{\partial z}$

and

$w=\frac{\partial \psi}{\partial x_{r}}$

the continuity equation for an incompressible liquid

$\frac{\partial u}{\partial x_{r}}+\frac{\partial w}{\partial z}$

is automatically fulfilled. The assumption of irrotational flow curl $\vec{v}=\operatorname{rot} \vec{v}=\overrightarrow{0}$, which for plane flow reads:

$\frac{\partial w}{\partial x_{r}}-\frac{\partial u}{\partial z}$

If equation (B-1) and equation (B-2) are substituted into (B-4), the result reads:

$\frac{\partial^{2} \psi}{x_{r}^{2}}+\frac{\partial^{2} \psi}{z^{2}}=0$ 
i.e. $\psi$ must fulfill the Laplace equation. The flow is sketched in Figure 3.1. The kinematic boundary conditions (no flow across a stream line) reads:

$\psi=Q \quad$ for $z=-h$

and

$\psi=0 \quad$ for $z=\eta$

Here the discharged $Q$ through a vertical section is given by

$Q=\int_{-h}^{\eta} u d z$

The dynamic boundary condition at the free surface reads: $p=$ constant and substitution into the generalized Bernoulli equation gives:

$g \eta+\frac{1}{2}\left(u^{2}+w^{2}\right)+\frac{\partial \varphi}{\partial t}=R \quad$ for $z=\eta$

where $\frac{\partial \varphi}{\partial t}=0$ due to steady flow. $R$ is named the Bernoulli constant. The main idea in the theory is the assumption that the stream function may be approximated by :

$\psi\left(x_{r}, z\right)=c_{r}(z+h)+\Sigma_{j=1}^{N} B_{j} \frac{\sinh j k(z+h)}{\operatorname{coshjkh}} \operatorname{cosjk} x_{r}+Q$

The right hand side of equation (B-10) may be interpreted as a truncated Fourier- series of an even function. For waves symmetrical about the wave crest the stream function must be an even function, and we may therefore expect that the equation (B-10) will approximate $\varphi$ arbitrarily well if $N$ es chosen big enough.

It is also seen that the expression for $\varphi$ fulfills both the bottom condition (B-6) and the Laplace equation, because the individual terms all fulfills the two equations. Notice also that an assumption of periodicity is hidden in equation (B-10), because $\varphi\left(x_{r}, z\right)=\varphi\left(x_{r}+L, z\right)$. To calculate the stream function we therefore need to determine the $N$ unknown coefficients $B_{j}, c_{r}$, $\operatorname{kor}(L)$ and $Q$ (in total $N+3$ unknown). This is done by exact fulfillment of the free surface conditions at $N+1$ points. The kinematics BC (B-7) reads:

$\varphi\left(x_{r}, \eta\right)=0=c_{r}(\eta+h) \sum_{j=1}^{N} B_{j} \frac{\sinh j k(\eta+h)}{\operatorname{coshjkh}} \operatorname{cosj} k x_{r}+Q$

and the dynamic $\mathrm{BC}(\mathrm{B}-9)$ reads

$g \eta+\frac{1}{2}\left(\left(-\frac{\partial \varphi}{\partial z}\right)^{2}+\left(\frac{\partial \varphi}{\partial x_{r}}\right)^{2}\right)=R$

or

$g \eta+\frac{1}{2}\left[-c_{r}-k \sum_{j=1}^{N} j B_{j} \frac{\cosh j k(\eta+h)}{\cosh j k h} \operatorname{cosj} k x_{r}\right]^{2}+\frac{1}{2}\left[-k \sum_{j=1}^{N} j B_{j} \frac{\sinh j k(\eta+h)}{\operatorname{coshj} k h} \operatorname{sinj} k x_{r}\right]^{2}=R$ 
In this way $2 N+2$ equations are set up and apparently the system of equations seems to be over-determined. However, the $\eta$ - values at the $N+1$ point are also unknown, giving: $\eta_{j}(\mathrm{~N}+1$ values), $B_{j}$ (N values) plus $c_{r}, k, Q$ and $R$, in total $2 N+5$ unknown. Therefore we must set up 3 extra equations in order to solve the system of equations. Incompressible fluid corresponds to

$\bar{\eta}=\frac{1}{L} \int_{0}^{L} \eta \cdot d x_{r}=0$

and the two definitions

$H=\eta_{\max }-\eta_{\min }$

$L=c_{r} T$

gives the two last equations necessary to solve the system. Notice that the equations are nonlinear, but practice has shown that the non-linear equations can be solved by use of a generalized Newton-Raphson iteration. After the solution of the system, the velocity potential $\varphi$ is calculated by (B-10) and $(u, w)$ by use of (B-1) and (B-2). It should be remembered that $u$ in equation (B-1) has to be adjusted with the velocity $c_{r}$, when particle velocities with respect to the bottom are calculated 


\section{APPENDIX C Snapshots of the experimental campaign}

This appendix shows pictures of the laboratory experiment, that was conducted at Grossen WellenKanal (GWK) in Hannover. A large number of tests of regular, freak and irregular waves were carried out. This experiment appears to be unique and was designed with the goal of developing a model for the run-up height, under breaking waves conditions. In overall, the objective of the experimental study was to obtain a quality and realistic data set under different conditions. 

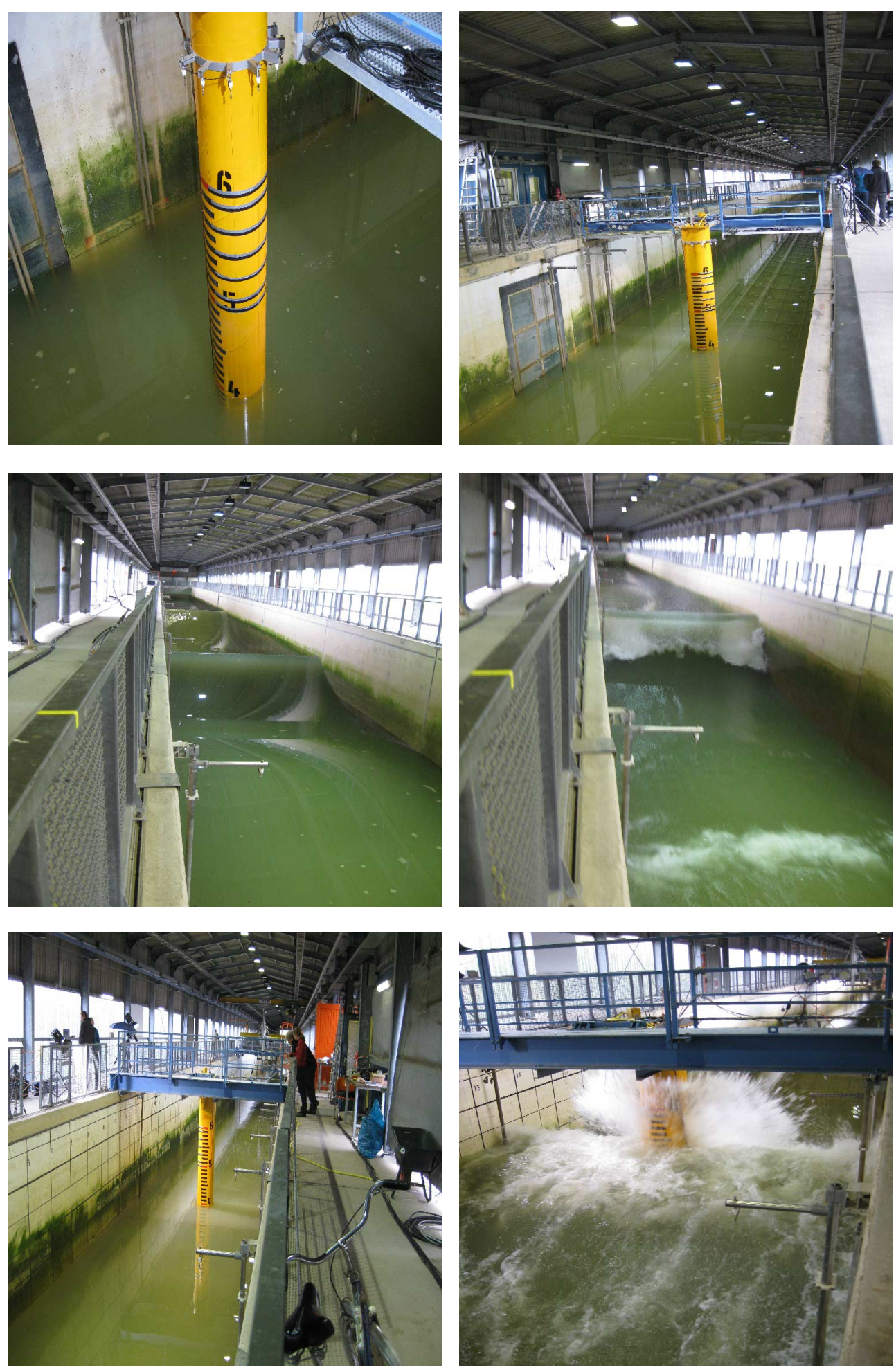

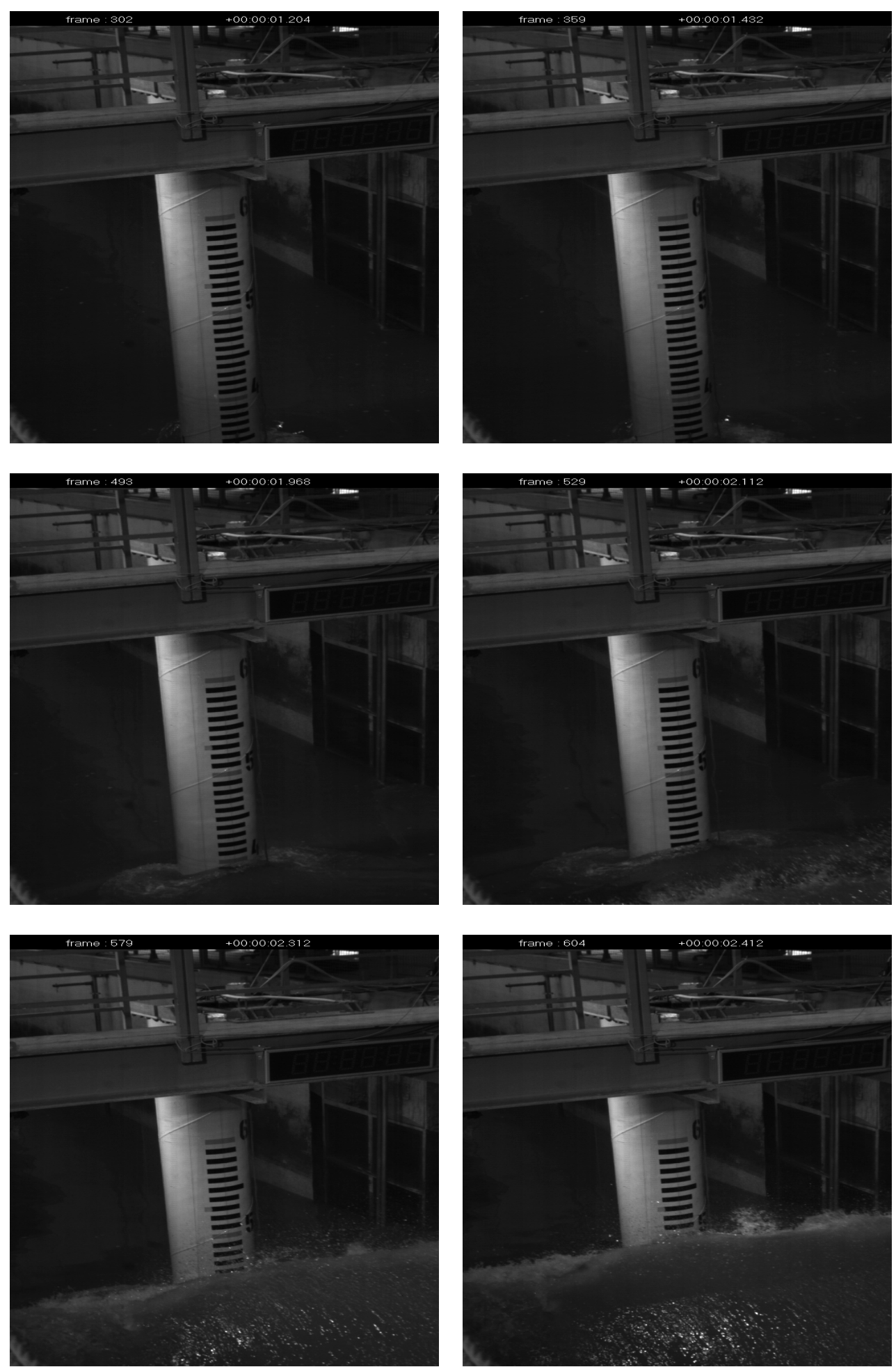

Figure C.2: Snapshot of the breaking waves impacting on the cylinder. Wave condAtig4st, 24012 $1.03, T=4.6$ 

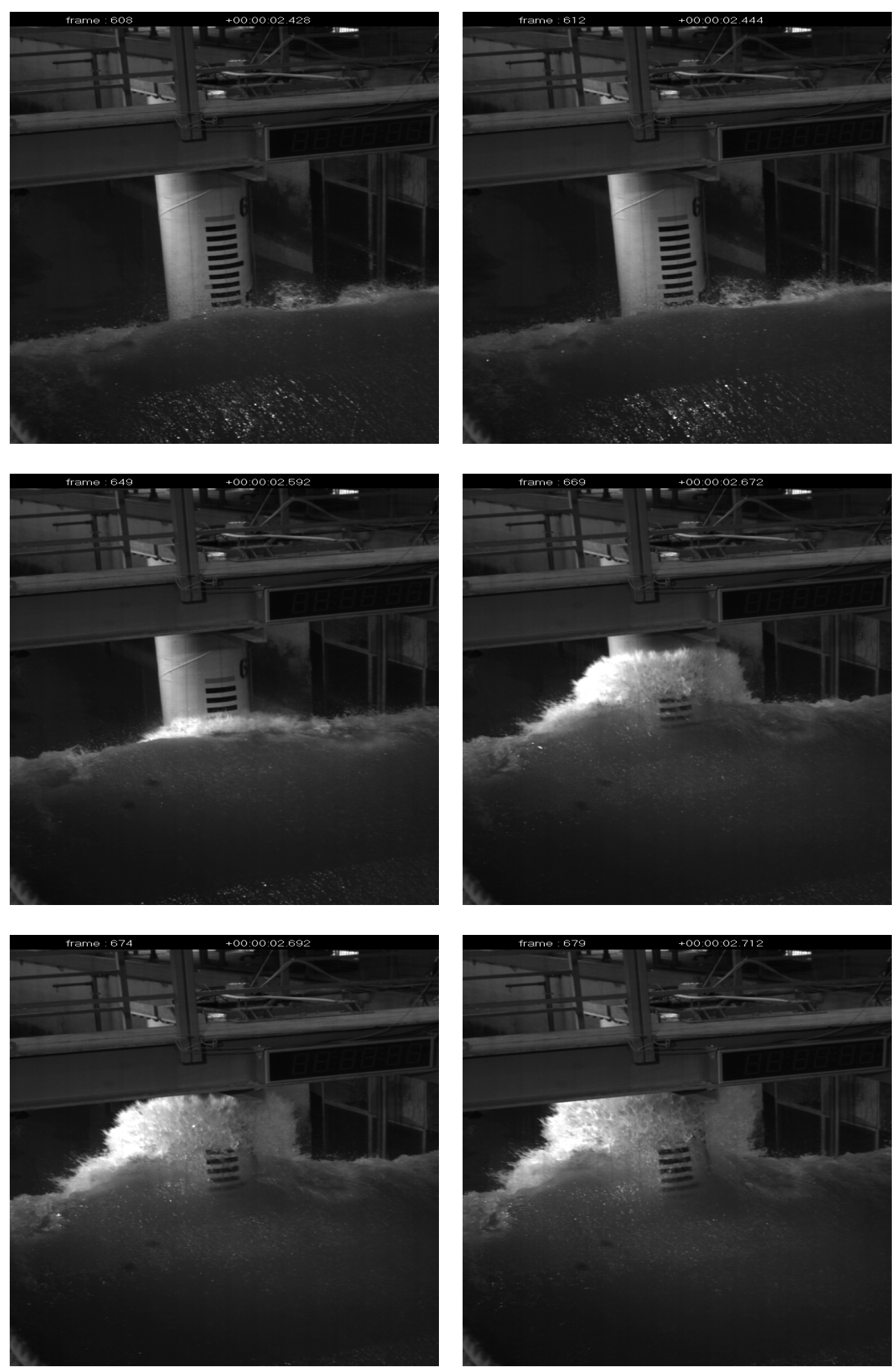

Pqugeramiresnapshot of the breaking waves impacting on the cylinder. Wave conditions $H=$ $1.03, T=4.6$ 

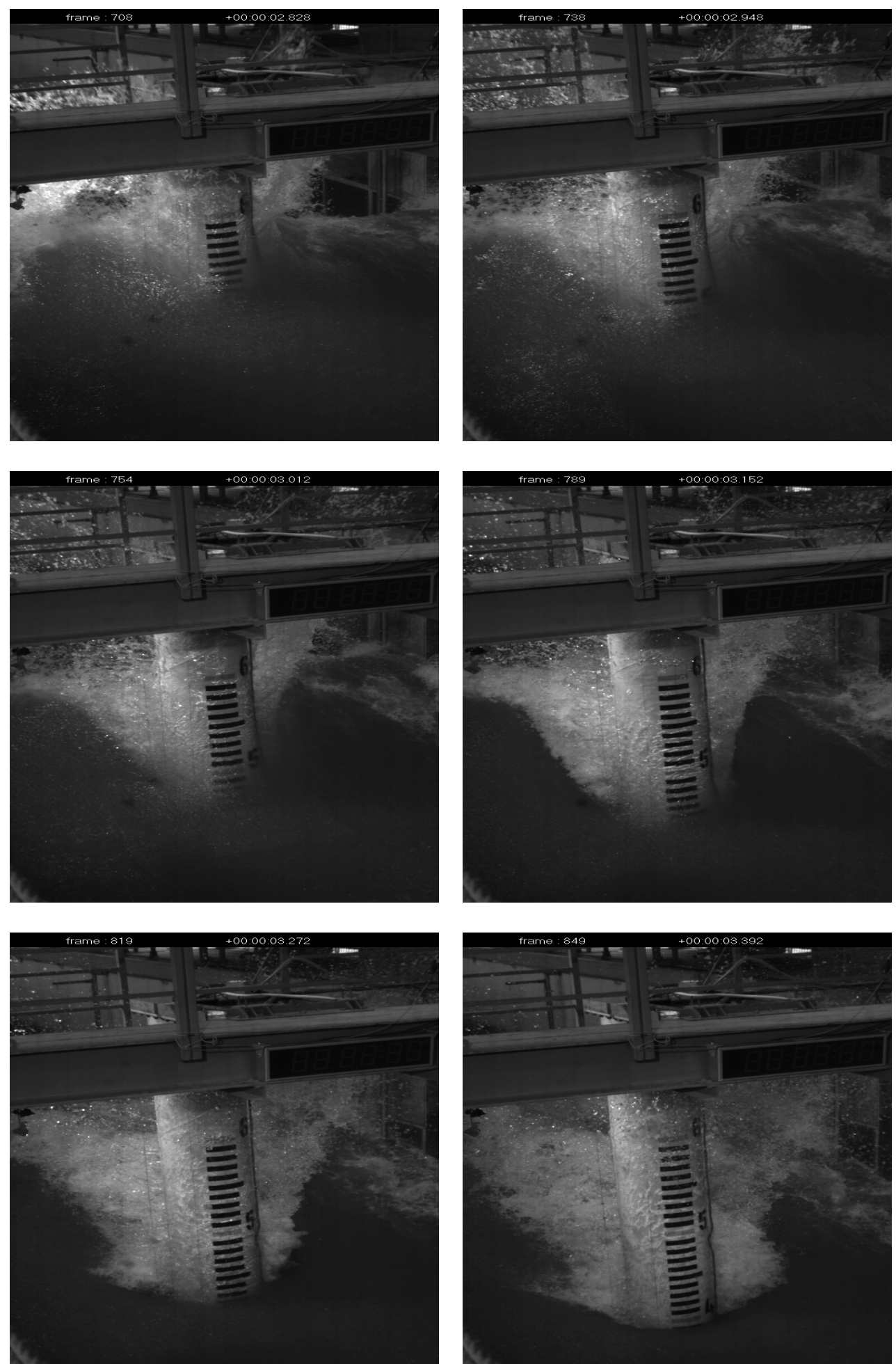

Figure C.4: Snapshot of the breaking waves impacting on the cylinder. Wave condAtig4st,12012 $1.03, T=4.6$ 